\title{
Der Nazis neue Kleider: Die Vereinnahmung jugendlicher Subkulturen durch die extreme Rechte in Deutschland
}

\author{
Tobias Leo \\ Kerngebiet: Zeitgeschichte \\ eingereicht bei: Ass.-Prof. ${ }^{\text {in }}$ Mag. ${ }^{\text {a }}$ Dr. ${ }^{\text {in }}$ Eva Pfanzelter (MA) \\ eingereicht im Semester: WS 2014/15 \\ Rubrik: SE-Arbeit
}

\section{Abstract \\ The Nazis' New Clothes: The Take-over of Youth Subcultures by right- wing Extremists in Germany}

\begin{abstract}
Right-wing extremist parties, organisations and movements tried and still try to take over youth subcultures. For about ten years, the right-wing extremist group Autonomous Nationalists has been trying to take over and copy leftwing movements, however more subtly and on a much broader social base than with the skinheads. This paper focuses on the take-over of the skinhead subculture by right-wing extremists as well as their attempt to reach left-wing subcultures as Autonomous Nationalists. The Hegemony Theory by Antonio Gramsci, a Marxist, is used as an explanatory model.
\end{abstract}

\section{Einleitung}

„[Da] Aktionsformen, Subkulturen, Aussehen, Farben, usw. nun mal kein Copyright besitzen, [...] [und] niemand ein Recht darauf hat, dies allein für sich zu beanspruchen", so schreiben die Autonomen Nationalisten (AN) Ostfriesland in ihrem Blog, zielen sie drauf ab, „jegliche Jugendsubkulturen zu unterwandern und sie für [...] [sich] zu gewinnen".2 Das altbekannte Bild von Neonazis - kahl rasierte Köpfe, Bomberjacken

Blog: Autonome Nationalisten Ostfriesland, Über uns, November 2008, [http://logr.org/leerostfriesland/uberuns/], eingesehen 27.11.2014.

2 Blog: AN Ostfriesland, Über uns. 
und glänzend polierte Springerstiefel samt weißen Schnürsenkeln - hat schon seit längerem ausgedient. Diese sogenannten Skinheads machen zwar immer noch einen Teil der Szene aus, dennoch tritt dieses Erscheinungsbild gegenüber einem moderneren, subtileren und unauffälligeren Aussehen deutlich in den Hintergrund. Die neuen Neonazis sind hingegen nur noch mit geübtem Blick von alternativen bzw. linksautonomen Jugendlichen zu unterscheiden, da sie ursprünglich „linke“ Kleidungsstile, Symbole und Agitationsformen vereinnahmen und für sich beanspruchen. Dasselbe gilt für die Musik, eines der wichtigsten Rekrutierungswerkzeuge für Rechtsextreme: War früher nur der Rechtsrock von Bedeutung, ist heute die gesamte musikalische Palette mit rechtsextremen Inhalten versetzt.

Die heterogene und zersplitterte Szene zwischen Kameradschaften, autonomen Nationalisten, Rechtsintellektuellen und rechtsextremen bzw. rechtspopulistischen Parteien verbindet ein Ziel: die Herbeiführung einer Kulturrevolution von rechts. Dabei spielt auch die Vergangenheit eine zentrale Rolle: Mit einer eigenen Geschichtspolitik zwischen Verharmlosung und Revisionismus der nationalsozialistischen Vergangenheit versucht das gesamte Spektrum von rechtsideologischen Gruppierungen einen Gegenpol zur vorherrschenden demokratischen Auffassung von Geschichte ${ }^{3}$ zu etablieren. Das Ziel dieser Arbeit ist es, die Vereinnahmung von jugendlichen Subkulturen durch Neonazis anhand des Hegemoniebegriffs in der Theorie des italienischen Marxisten Antonio Gramsci (1891-1937) nachzuzeichnen. Wie in dessen Konzeption von Metapolitik soll der vorpolitische Raum erobert und die Meinungsführerschaft erlangt werden, so die These dieser Arbeit. Ein Teil des vorpolitischen Raums sind jugendliche Subkulturen einschließlich Musik, Lebensstil, Modetrends und Protestformen. Als Musterbeispiel bietet sich die Skinheadbewegung an: Die ursprünglich unpolitische Skinheadszene wurde erfolgreich von Rechtsextremisten unterwandert, sodass der Begriff "Skinhead" heute im kollektiven Gedächtnis als Synonym für "Neonazi" bzw. „Neofaschist" gilt. Ein ähnliches Phänomen, jedoch in einer ganz neuen Qualität, ist die relativ neue und dynamische Bewegung der Autonomen Nationalisten. Mit der Übernahme von genuin linken Symbolen, Agitationsformen und Kleidungsstilen treten sie in modernem Gewand auf, die Botschaften sind jedoch dieselben geblieben. Querfrontstrategien, z.B. bei sozialen oder umweltpolitischen Themen spielen ebenfalls eine Rolle, um rechtsextreme Werte in die Mitte der Gesellschaft zu befördern und damit im kollektiven Bewusstsein bzw. Gedächtnis zu verankern.

Laut Maurice Halbwachs zielt das kollektive Gedächtnis auf das Bestreben einer Gruppe in der Gegenwart ab und "dabei sind Verzerrungen und Umgewichtungen bis hin zur Fiktion möglich".4 Die größte Gefahr ist hier laut Jan-Werner Müller die Rekonfiguration des kollektiven Gedächtnisses als Impulsgeber für Aggressionen. ${ }^{5}$ Eine tragende

3 Stefan Troebst, Geschichtspolitik. Politikfeld, Analyserahmen, Streitobjekt, in: Etienne Francois/Kornelia Konczal/ Robert Traba/Stefan Troebst (Hrsg.), Geschichtspolitik in Europa seit 1989. Deutschland, Frankreich und Polen im internationalen Vergleich (Moderne europäische Geschichte 3), Göttingen 2013, S. 15-34, hier S. 19 f.

$4 \quad$ Astrid Erll, Kollektives Gedächtnis und Erinnerungskulturen. Eine Einführung, Stuttgart-Weimar 2005, S. 17.

5 Jan-Werner Müller, Introduction: The Power of Memory, the Memory of Power and the Power over Memory, in: Ders. (Hrsg.), Memory and Power in Post-War Europe. Studies in the Presence of the Past, Cambridge 2002, S. 1-35, hier S. 21. 
Rolle spielt nach wie vor die Musik, aber vor allem die neuen Möglichkeiten des Internets, das zum wohl wichtigsten Propagandamedium aufgestiegen ist. Vorzugsweise noch ungefestigte Jugendliche und junge Erwachsene sind hier zentrale Zielgruppen, was sich in der Hereinnahme von zahlreichen jugendaffinen und popkulturellen Elementen offenbart. Im Zuge dessen wird sogar vor den zuvor verachteten und als "undeutsch" definierten Anglizismen nicht (mehr) zurückgeschreckt.

\section{Methodik}

Zuerst wird der Hegemoniebegriff im Sinne von Gramsci geklärt, mithilfe dessen die erfolgreiche Übernahme der Skinheadbewegung in England und Deutschland überprüft werden soll. Dabei wird besonders auf die Eigenheiten der Subkultur, die Übernahme von rechtsextremem Gedankengut und schließlich die Instrumentalisierung seitens rechtsextremer Parteien eingegangen. Basierend auf dem Zusammenspiel der rechtsextremen Skinheadsubkultur und den Freien Kameradschaften wird in weiterer Folge die Entwicklung der Autonomen Nationalisten dargestellt. Hierbei ist zu erwarten, dass die Vereinnahmungsstrategien auf eine viel breitere gesellschaftliche Basis angelegt sind als noch in der Skinheadbewegung, da diese sich aufgrund ihres offenen Bekenntnisses zu ihrer Ideologie und ihres martialischen Auftretens an den Rand des Mainstreams brachten. Im Fokus stehen dabei zwei verschiedene Ebenen: eine methodische mit der Übernahme von genuin linksorientierten bzw. alternativen Symbolen, Lifestyles, politischen Positionen, Agitationsformen und Kleidungsstilen sowie eine mediale mit dem Internet, das den Rechtsextremen schier unbegrenzte Möglichkeiten zur Verbreitung ihrer Propaganda bietet. Zuletzt ist die Musik von zentraler Bedeutung, der ein eigenes Kapitel gewidmet ist. Das Spektrum hat sich diesbezüglich stark verbreitert und ausgehend vom Rechtsrock wird diese Ausdifferenzierung nachgezeichnet. Zum Dokumentieren von einschlägigen Internetseiten diente das Linux-Programm "wget”. Alle zitierten Videos wurden mit dem Firefox-Add-on „DownloadHelper 4.9.24" heruntergeladen und auf die lokale Festplatte des Autors gespeichert.

\section{Forschungsüberblick}

Zum Thema Rechtsextremismus ist bereits eine Vielzahl an Publikationen erschienen, sowohl allgemeine als auch zu speziellen Themen wie der Skinheadbewegung und vor allem in letzter Zeit verstärkt zum Phänomen der AN. Folgender Überblick ist nur eine kleine Auswahl, die das Thema dieser Arbeit abdecken soll. Mit "Skinheads - Portrait einer Subkultur"6 behandelt Christian Menhorn die Skinheadsubkultur von den Anfängen bis zum Beginn des 21. Jahrhunderts in ihren verschiedenen Facetten. Ein besonderes Augenmerk legt er dabei auf die rechte Skinheadkultur Deutschlands. Einen ähnlichen Weg gehen Klaus Farin und Eberhard Seidel-Pielen in der journalistischen Studie "Skinheads", die mittlerweile ein Standardwerk geworden ist. Beide Studien le- 
gen auch besonderen Wert auf die Ausprägungen rechtsextremer Skinheadmusik. Der Sammelband "Strategien der extremen Rechten" ${ }^{\text {"8 }}$ bietet einen reichhaltigen Überblick über die Vorgehensweisen von Rechtsextremen, sowohl innerhalb und außerhalb der Nationaldemokratischen Partei Deutschlands (NPD) als auch in kulturbezogener und in rechtlicher Hinsicht. Ein anderer Zugang wird in „Rechte Diskurspiraterien“9 gewählt, wobei die Einbettung von linken Elementen in die rechtsextreme Ideologie im Vordergrund steht. Der Sammelband "Autonome Nationalisten. Neonazis in Bewegung"10 rückt - wie der Name schon sagt - das Phänomen der AN in einer sozialwissenschaftlichen Perspektive ins Zentrum. Schließlich stellt Udo Baron in seinem Aufsatz „Das Selbstverständnis von Links- und Rechtsautonomen - Ein Vergleich zweier neuer subkultureller Erscheinungsformen"11 einen vergleichenden Blickwinkel zwischen Linksund Rechtsautonomen dar.

\section{Die Gefängnishefte Gramscis}

Etwas mehr als zehn Jahre war der Marxist und ehemalige Anführer der kommunistischen Partei Italiens Antonio Gramsci unter der faschistischen Herrschaft Mussolinis bereits inhaftiert. In einem katastrophalen körperlichen Zustand verstarb im Frühjahr 1937 an den Folgen einer Hirnblutung in Mussolinis Kerker. ${ }^{12}$ Dort verfasste er mit insgesamt 29 "Gefängnisheften"13 sein Hauptwerk, das er jedoch nie fertigstellen konnte. Die Hefte sind in Paragraphen unterteilt, jedoch weder systematisch noch thematisch angeordnet. Dies wurde auch in den kritischen Gesamtausgaben übernommen, um den Kontext nicht zu zerreißen und so die gedanklichen Entwicklungsprozesse Gramscis zu bewahren. ${ }^{14}$ Es dauerte allerdings bis 1991, bis der erste Band der deutschen kritischen Gesamtausgabe veröffentlicht wurde, die italienische ${ }^{15}$ - an der sich die deutsche orientiert - erschien bereits 1975. Zuvor gab es lediglich Zusammenstellungen von ausgewählten Teilen der Gefängnishefte. Das lag wohl auch an den ideologischen Schranken des Kalten Kriegs, jedoch konnten Gramscis Werke spätestens nach dem Zerfall der Sowjetunion neu bewertet werden.

Der fragmentarische Charakter der Gefängnishefte macht das Lesen Gramscis zu einer Herausforderung und manchmal auch zur Suche nach der Nadel im Heuhaufen, die jedoch durch einen eigenen Registerband erheblich erleichtert wird. Zudem sind seit den 1970er-Jahren zahlreiche Publikationen zum einfacheren Einstieg in Gramscis Gedankenwelt erschienen. Rund um den zentralen Begriff der Hegemonie kristallisiert

8 Stephan Braun/Alexander Geisler/Martin Gerster (Hrsg.), Strategien der extremen Rechten. Hintergründe - Analysen - Antworten, Wiesbaden 2009.

9 Regina Wamper/Helmut Kellersohn/Martin Dietzsch (Hrsg.), Rechte Diskurspiraterien. Strategien der Aneignung linker Codes, Symbole und Aktionsformen, Münster 2010.

10 Jan Schedler/Alexander Häusler (Hrsg.), Autonome Nationalisten. Neonazis in Bewegung, Wiesbaden 2011.

11 Udo Baron, Das Selbstverständnis von Links- und Rechtsautonomen - Ein Vergleich zweier neuer subkultureller Erscheinungsformen, in: Gerhard Hirscher/Eckhard Jesse (Hrsg.), Extremismus in Deutschland. Schwerpunkte, Vergleiche, Perspektiven, Baden-Baden 2013, S. 435-453.

12 Antonio Gramsci, Gefängnishefte. Kritische Gesamtausgabe, Heft 1, Bd. 1, Hamburg 22012, S. 65.

13 Ders., Gefängnishefte. Kritische Gesamtausgabe, 10 Bde., Hamburg 22012.

14 Ders., Gefängnishefte 1, S. 11.

15 Ders., Quaderni del carcere, 4 Bde., Turin 1975. 
sich ein wahres Begriffsnetzwerk von immer wieder vorkommenden Schlüsselbegriffen heraus, die sich einander beeinflussen, z.B. Zwang, Konsens, Zivilgesellschaft, Bildung, Subalternität, Fordismus oder Alltagsverstand. Aus dieser unsystematischen Ansammlung von Paragraphen ist im Gesamten eine fundierte, tiefgreifende und vielschichtige Theorie zu erkennen, auch wenn sie den fragmentarischen Charakter nie zur Gänze verliert.

Die ewige Konstante in der Literatur über Gramsci ist der zentrale Begriff der Hegemonie. In der älteren Forschung der 1970er-Jahre war jedoch das Interesse häufig auf die Sonderrolle Gramscis innerhalb des Marxismus gerichtet. ${ }^{16}$ Dieser lehnte einen strikten Dogmatismus ab, was ein wichtiger Bestandteil seiner Überlegungen war. Nach dem Erscheinen der italienischen kritischen Gesamtausgabe stand in weiterer Folge der Begriff der Hegemonie im Zentrum der Betrachtungen, wobei der Hegemoniebegriff sowohl mit institutionellen bzw. staatlichen ${ }^{17}$ als auch im Laufe der 1980er-Jahre immer mehr mit kulturellen Gesichtspunkten ${ }^{18}$ verknüpft wurde. Anfang der 1990er fällt auf, dass Gramsci vermehrt in Verbindung mit internationalen Beziehungen rezipiert wurde. ${ }^{19}$ Seither erweiterte sich die Bandbreite der Zugänge zu den Gefängnisheften immer mehr und es erschienen Publikationen über einzelne Schlüsselbegriffe Gramscis wie Erziehung bzw. Bildung, Zivilgesellschaft oder Alltagsverstand. Neben der Neuaufbereitung älterer Fragestellungen wurde in jüngster Vergangenheit eine große Anzahl von Literatur mit verschiedensten Ansätzen veröffentlicht, etwa indem Gramsci in ein Verhältnis zu Globalisierung, Neoliberalismus, Gesundheitsförderung, Genderaspekten oder Klimawandel gesetzt wurde. ${ }^{20}$ Obwohl die Forschungsschwerpunkte aktuell eher auf ein sozialwissenschaftliches Interesse hindeuten, kommen historische Betrachtungsweisen aber auf keinen Fall zu kurz.

\section{Begriffsdefinitionen}

\section{Gramscis Hegemoniebegriff}

Zunächst soll Gramscis Konzept der Erlangung von kultureller und moralischer Hegemonie im vorpolitischen Raum beleuchtet werden. Wie bereits angedeutet, ist Hegemonie der zentrale Begriff in seinen Theorien. Dabei soll festgehalten werden, dass für diese Arbeit allein die Methode zur Erlangung der Hegemonie von Bedeutung ist. Sonstige Ansichten bezüglich seiner politischen Ausrichtung werden hier nicht berücksichtigt. Der vorpolitische Raum wird von Gramsci umschrieben als „die materiel-

\footnotetext{
16 Christian Riechers, Antonio Gramsci. Marxismus in Italien, Frankfurt am Main 1970.

17 Valentino Gerratana, Staat, Partei, Institutionen. Politische Hegemonie der Arbeiterklasse, in: Biago de Giovanni/ Valentino Gerratana/Leonardo Paggi (Hrsg.), Gramsci-Debatte 1. Hegemonie, Staat und Partei, Hamburg 1978, S. 32-47.

18 Claus Leggewie, Kulturelle Hegemonie. Gramsci und die Folgen, in: Leviathan 15 (1987), S. 285-304.

19 Robin Jacobitz, Antonio Gramsci-Hegemonie, historischer Block und intellektuelle Führung in der internationalen Politik (Arbeitspapiere der Forschungsgruppe Europäische Gemeinschaften 5), Marburg 1991, [http://edoc. vifapol.de/opus/volltexte/2013/4336/pdf/a5.pdf], eingesehen 29.3.2016.

20 International Gramsci Society, Gramsci Bibliography: 2015, 3.3.2016, [http://www.internationalgramscisociety. org/bibliography/index.html], eingesehen 29.3.2016.
} 
le Organisation, die darauf gerichtet ist, die theoretische oder ideologische ,Front' zu bewahren, zu verteidigen und zu entfalten“.21 Die wichtigste Rolle schreibt er dabei der Presse bzw. den Medien zu, aber auch z.B. Schulen, Bibliotheken, Architektur oder Straßennamen spielen eine wesentliche Rolle. ${ }^{22}$ In die heutige Zeit übertragen ist diesbezüglich wohl das Internet der wichtigste und dynamischste von allen Bereichen.

Gramsci zufolge ist die staatliche Macht nicht direkt zu erlangen, es erfordere eine "Wende vom Bewegungskrieg [...] zum Stellungskrieg".23 Diese Metapher bezieht sich auf die Stellungskriege im Ersten Weltkrieg, wonach ein frontaler (politischer) Angriff auf den westeuropäischen Staat fatal wäre, da dieser durch die zivilgesellschaftlichen Strukturen gleich militärischen Schützengräben vor Einbrüchen geschützt werde. ${ }^{24}$ So komme es in diesen Grabenkämpfen besonders darauf an, den vorpolitischen Raum nichtmilitärisch zu erobern und dort eine kulturelle, moralische und intellektuelle Hegemonie zu erreichen, um in weiterer Folge die Staatsmacht dauerhaft zu erobern. ${ }^{25}$ Nach Gramsci muss eine gesellschaftliche Gruppe zuerst führend sein, bevor sie herrschend werden kann. ${ }^{26}$ Hegemonie bedeutet für ihn aber nicht nur die Herrschaft mittels Zwang über andere gesellschaftliche Gruppen, sondern auch durch Konsens. So schreibt er:

„Die ,normale' Ausübung der Hegemonie [...] zeichnet sich durch eine Kombination von Zwang und Konsens aus, die sich die Waage halten, ohne daß der Zwang den Konsens zu sehr überwiegt, sondern im Gegenteil vom Konsens der Mehrheit, [...] getragen erscheint." 27

Das setzt voraus, dass bereits vor der Erlangung von Hegemonie ein gewisser Konsens mit anderen gesellschaftlichen Gruppen erreicht werden muss. Laut Gramsci müssen „gegenhegemoniale Bewegungen als Impulsgeber für ein neues politisch-ethisches Denken agieren [...], Orientierungen vorgeben [...], Richtungen aufzeigen und eigene ,Wahrheiten' vergesellschaften".28 Mit dieser (Querfront-)Strategie soll eine Akzeptanz von anderen Gruppen zu bestimmten Themen erreicht werden, um so die eigenen Positionen tiefer in die Gesellschaft und somit in das kollektive Bewusstsein einfließen zu lassen. Verständlicherweise ist das ein langer Prozess und kann nicht von heute auf morgen geschehen. Denn „Veränderungen [...] treten nicht durch rasche und verallgemeinerte,Explosionen' ein, sie treten meistens durch, sukzessive Kombinationen' nach äußerst disparaten,Formeln' ein".29

Antonio Gramsci, Gefängnishefte. Kritische Gesamtausgabe. Hefte 2 und 3, Bd. 2, Hamburg 22012, S. 373

Ebd., S. 373 f.

Antonio Gramsci, Gefängnishefte. Kritische Gesamtausgabe. Hefte 6 und 7, Bd. 4, Hamburg 22012, S. 873. Mikiya Heise/Daniel vom Fromberg, „Die Machtfrage stellen“. Zur politischen Theorie Antonio Gramscis, in: Andreas Merkens/Victor Rego Diaz (Hrsg.), Mit Gramsci arbeiten. Texte zur politisch-praktischen Aneignung Antonio Gramscis (Argument Sonderband Neue Folge AS 305), Hamburg 2007, S. 110-125, hier 118 f.

Gerhard Roth, Gramscis Philosophie der Praxis. Eine neue Deutung des Marxismus, Düsseldorf 1972 , S. 134.

Gramsci, Gefängnishefte 1, S. 101.

Ebd., S. 120.

Andreas Merkens, „Die Regierten von den Regierenden intellektuell unabhängig machen“. Gegenhegemonie, politische Bildung und Pädagogik bei Antonio Gramsci, in: Merkens/Diaz (Hrsg.), Mit Gramsci arbeiten, S. 157-174, hier S. $162 \mathrm{f}$.

Gramsci, Gefängnishefte 1, S. 94. 
Eine Schlüsselrolle schreibt Gramsci den Intellektuellen innerhalb einer gesellschaftlichen Gruppe zu: Sie wirken nicht im Bereich der direkten Herrschaft des Staates, sondern in privaten Institutionen wie Vereinen, Gewerkschaften, Schulen etc., um die Ideologie zu stützen oder zu verändern. ${ }^{30}$ Eine gesellschaftliche Gruppe, die nach Hegemonie strebt, muss danach trachten, „sowohl [...] eigene [...] Intellektuelle hervorzubringen, als auch besonders die traditionellen Intellektuellen zu,erobern "'.31 Diese Prinzipien gab es mit Sicherheit schon vor Gramsci, er war jedoch der erste, der sie in dieser Form niederschrieb hat. Es ist auch nicht nur für linksgerichtete Bewegungen anwendbar, sondern für Weltanschauungen jeder Art. So bezieht sich die Neue Rechte auf akademischer Ebene ebenfalls auf den Hegemoniebegriff Gramscis. ${ }^{32}$ Mit diesem Konzept der Hegemonie sollen in den folgenden Kapiteln die Strategien der extremen Rechten zur Vereinnahmung von Jugendbewegungen überprüft werden.

\section{Rechtsextremismus}

Bei der Definition von Rechtsextremismus gehen die Meinungen in der Forschungswelt weit auseinander und es existiert folglich keine allgemein akzeptierte Definition. Der Begriff ist z.B. vom deutschen Verfassungsschutz eher eng ausgelegt ${ }^{33}$ : Er unterscheidet strikt zwischen links, rechts sowie der Mitte und zielt lediglich auf die Verfassung ab. Daher macht es hier eher Sinn, einen politikwissenschaftlichen und eher weit ausgelegten Rechtsextremismusbegriff zu verwenden, vor allem unter dem Gesichtspunkt, dass in dieser Arbeit die Vereinnahmung von nichtrechten Bereichen der Gesellschaft im Fokus steht. Passend dafür ist die Definition von Richard Stöss:

„Unter ,Rechtsextremismus' verstehen wir die Gesamtheit von Einstellungen, Verhaltensweisen und Aktionen, organisiert oder nicht, die von der rassisch oder ethnisch bedingten sozialen Ungleichheit der Menschen ausgehen, nach ethnischer Homogenität von Völkern verlangen und das Gleichheitsgebot der Menschenrechts-Deklarationen ablehnen, die den Vorrang der Gemeinschaft vor dem Individuum betonen, von der Unterordnung des Bürgers unter die Staatsräson ausgehen und die den Wertepluralismus einer liberalen Demokratie ablehnen und Demokratisierung rückgängig machen wollen. Unter, Rechtsextremismus' verstehen wir insbesondere Zielsetzungen, die den Individualismus aufheben wollen zugunsten einer völkischen, kollektivistischen, ethnisch homogenen Gemeinschaft in einem starken Nationalstaat und in Verbindung damit den Multikulturalismus ablehnen und entschieden bekämpfen. Rechtsextremismus ist eine antimodernistische, auf soziale Verwerfungen industrie-

30 Roth, Philosophie, S. 110.

31 Ebd., S. 112.

32 Steffen Kailitz, Politischer Extremismus in der Bundesrepublik Deutschland. Eine Einführung, Wiesbaden 2004, S. 85 .

33 Richard Stöss, Rechtsextremismus im Wandel, Berlin 201033, S. 10-18, [http://library.fes.de/pdf-files/do/08223.pdf], eingesehen 4.1.2015. 
gesellschaftlicher Entwicklung reagierende, sich europaweit in Ansätzen zur sozialen Bewegung formierende Protestform." ${ }^{34}$

\section{Skinheads}

Die Skinheadbewegung unterlag einem stetigen Wandel und ist eine sehr heterogene Subkultur mit verschiedenen Strömungen, was sich auch in den politischen Einstellungen der jeweiligen Ausprägungen niederschlägt. Eine allgemein gültige Definition von Skinheads ist daher schwierig. Lediglich hinsichtlich des Erscheinungsbildes sowie der Organisationsstruktur kann eine idealtypische Definition herangezogen werden.

„Als Skinhead wird ein Jugendlicher oder junger Erwachsener bezeichnet, dessen auffälligstes Merkmal der kahl rasierte Schädel ist. Zur szenetypischen Kleidung gehören vor allem eine Bomberjacke (meist grün, blau oder schwarz), schwere, manchmal mit Stahlkappen versehene Arbeitsschuhe (z. B. Doc-Martens) und hochgekrempelte Jeans sowie Hosenträger (Braces). Skinheads sind nur lose organisiert, vereinsähnliche Strukturen von Skinheads gibt es nur selten." ${ }^{\text {35 }}$

\section{Die rechte Skinheadkultur}

\section{Entstehung in Großbritannien}

Skinheads entstanden im Arbeitermilieu im London der 1960er-Jahre. Ihrem Selbstverständnis zufolge waren sie die Vertreter der sich im Untergang befindenden englischen Working Class. ${ }^{36}$ Das Jahr 1969 gilt innerhalb der Szene als Entstehungsjahr der Skinheads, auch in der englischen Presse ${ }^{37}$ fand der Ausdruck Skinhead erstmals Erwähnung. Natürlich entstand diese Subkultur nicht aus dem Nichts, sondern hatte - ohne jetzt darauf näher einzugehen - mit den Mods, den Rude Boys (jamaikanische Einwanderer) und den Boot Boys (Vorgänger der Hooligans) Vorläufer in den 1960er-Jahren. Sie weisen gewisse gemeinsame Merkmale auf: Sie hatten einen Kurzhaarschnitt, ${ }^{38}$ waren gewaltbereit und kamen größtenteils aus unterprivilegierten Schichten ${ }^{39}$. Die Bezeichnung Skinhead leitet sich vom Kurzhaarschnitt ab, da die Kopfhaut durchschimmerte. Jedoch waren Glatzen zur Anfangszeit noch nicht üblich. ${ }^{40}$ Geschorenen Haare waren in der Vergangenheit häufig ein Zeichen von Repression. Die Konzentrationslager, Gulags, Guantanamo oder die alltestamentarische Geschichte von Samson sind nur einige Beispiele. Im Fall der Skinheads war dieser Haarschnitt zwar selbst gewählt,

34 Hans-Gerd Jaschke, Rechtsextremismus und Fremdenfeindlichkeit. Begriffe, Definitionen, Praxisfelder, Wiesbaden $2001^{2}$, S. 30

35 Verfassungsschutz Norrhein-Westfalen, Skinheads und Rechtsextremismus, Düsseldorf 2001, S. 15, [http://www. mik.nrw.de/fileadmin/user_upload/Redakteure/Verfassungsschutz/Dokumente/Skinheads_und_Rechtsextremismus.pdf], eingesehen 3.12.2015. Ekkehard Sander, Skinheads - Gefangene des eigenen Mythos?, in: Deutsches Jugendinstitut (Hrsg.), Gewalt gegen Fremde. Rechtsradikale, Skinheads und Mitläufer, München 1993, S. 161-172, hier S. 164.

37 Menhorn, Skinheads, S. 21

38 Holger Bredel, Skinheads - Gefahr von Rechts?, Berlin 2002, S. 26.

39 Menhorn, Skinheads, S. 12-20.

40 Susanne El-Nawab, Skinheads - Ästhetik und Gewalt, Frankfurt am Main 2001, S. 19. 
aber dennoch aus ihrer Sicht als Zeichen der Unterdrückung zu deuten. Teilweise übernahmen die Skinheads die Kleidungsstile der vorangegangenen Subkulturen. Charakteristisch sind die groben Arbeiterstiefel, enge hochgekrempelte Jeans, Tätowierungen und seit den späten 1970ern millimeterkurze Haare bis zur Vollglatze. ${ }^{41}$

Seit Mitte der 1980er kamen Bomberjacken und andere Militärkleidung wie z.B. Camouflagehosen dazu. ${ }^{42}$ In ihrem Aussehen wollten sie sich - wie jede rebellische Subkultur - bewusst von der bürgerlichen Gesellschaft und anderen Subkulturen abgrenzen sowie Einheit und Zusammengehörigkeit demonstrieren. Hinsichtlich der politischen Einstellung waren sie in der Anfangszeit weder linksgerichtet, noch rechtsextrem eingestellt, eher wurden konservative Werte hochgehalten. ${ }^{43}$ Die Freizeitbeschäftigungen bestanden aus "Musik \& Spaß, Randale, Bier, Fußball, Kameradschaft, Sex und coole[n] Klamotten".44 Für jede jugendliche Subkultur ist die Musik immens wichtig: Sie transportiert Botschaften, Ideale, Lebenseinstellungen - sie gibt die Richtung vor und erzeugt Abgrenzung sowie gemeinsame Bezugspunkte. In der ersten Skingeneration entwickelte sich noch keine eigene Skinheadmusik, die bevorzugte Musikrichtung war der von farbigen Einwanderern importierte Musikstil des Ska, der Vorläufer des Reggae. ${ }^{45}$ Das bedeutete, dass auch schwarze Jugendliche zu Skinheads wurden. ${ }^{46}$ Die Skinheadkultur hat also multikulturelle Wurzeln, der gemeinsame soziale Status war wichtig und nicht die Hautfarbe oder andere Merkmale. Anders gesagt: Klassen- statt Rassenbewusstsein. Eine weitere wichtige Rolle spielte der Spaß an der Gewalt. Falls sie sich nicht gegenseitig bekämpften - etwa in der sogenannten dritten Halbzeit nach Fußballspielen - prügelten sie sich mit Ausländern oder Angehörigen anderer Subkulturen wie Rockern, Hippies und, Homosexuellen. ${ }^{47}$ In gewisser Weise war das eine Art Erlebniswelt, die eine große Anziehungskraft auf viele Jugendliche aus der Arbeiterschicht ausübte. Die nicht gerade objektive Medienberichterstattung der englischen Boulevardpresse führte schon früh dazu, dass Skinheads auf ausländerfeindliche Schläger reduziert wurden. ${ }^{48}$

Schien die Skinheadkultur bereits Anfang der 1970er wieder dem Ende zuzugehen, kehrte sie im Zuge der Punkbewegung, die im Sommer 1976 ebenfalls in London entstand, wieder auf die Bildfäche zurück. Wieder war die Musik enorm wichtig für die Bewegung: Der Punksound war einfach, roh und aggressiv. Mit meist nur drei, maximal vier Akkorden, einem rotzigen Gesang und gesellschaftskritischen Texten wusste man zu schockieren. Das Rebellentum des Punks zog Tausende von jungen Menschen an, doch innerhalb kürzester Zeit wurde die Bewegung kommerziell ausgeschlachtet und entwickelte sich zur Massenmodeerscheinung. ${ }^{49}$ In-Sein war bald wichtiger als

\footnotetext{
41 Bredel, Skinheads, S. 45.

42 Ebd.

43 El-Nawab, Skinheads, S. 21.

44 Ebd., S. 20

45 Menhorn, Skinheads, S. 33-36.

46 Farin/Seidel-Pielen, Skinheads, S. 34.

47 Bredel, Skinheads, S. $28 \mathrm{f}$.

48 Ebd., S. 28

49 Farin/Seidel-Pielen, Skinheads, S. 44.
} 
Missstände aufzuzeigen und in weiterer Folge wandten sich viele vom Punk, vor allem von den Mode- und Edelpunks, wieder ab. ${ }^{50}$ Das brachte der damals schon mehr oder weniger totgeglaubten Skinheadbewegung wieder regen Zulauf, vor allem aus der Punkszene. Der authentische Charakter der Bewegung und die aggressiven Klänge der Punkbands wurden beibehalten:51 Der Street- oder Oi!-Punk war geboren. Der Ausruf "Oi!" bedeutet soviel wie "Hey!"52 und stammt von den Cockney Rejects, die ihre Lieder mit "Oi, Oi, Oi!" einzählten.53 Die Prinzipien der Oi!-Bewegung waren „Zusammenhalt untereinander und die Abwesenheit von Dogmen".54

Die Skinheadbewegung ist seit jeher männerdominiert, ${ }^{55}$ und das zeigt sich sowohl im maskulinen und Härte ausstrahlenden Kleidungsstil als auch in ihren Werten und Verhaltensweisen. Zusammen mit der konservativen Einstellung sowie der Gewaltbereitschaft machte das später viele von ihnen empfänglich für rechtsextreme Weltanschauungen.

\section{Politisierung}

Sowohl in der Punk- als auch in der Skinheadbewegung wurden Mitte der 1970erJahre Nazi-Symbole demonstrativ verwendet, um zu provozieren und schockieren. Zunächst aber nicht, um explizit eine politische Botschaft auszudrücken. ${ }^{56}$ Doch bald begann die Politik, Einfluss zu nehmen und das nicht nur von rechts, sondern von allen Seiten. ${ }^{57}$ Die rechtsextreme Seite konnte dabei das größte Kapital daraus schöpfen. Die Jugendarbeitslosigkeit stieg zu dieser Zeit massiv an und zugleich nahm die Einwanderung aus Staaten des ehemaligen britischen Empires zu - rechtsextreme Einstellungen wurden immer mehr salonfähig..$^{58}$ In der britischen Gesellschaft war bereits in den späten 1960er-Jahren eine latent vorhandene Fremdenfeindlichkeit zu beobachten die rechtsextreme „National Front" (NF) wurde 1967 gegründet. ${ }^{59}$ Etwa zur selben Zeit machte der konservative Schattenminister Enoch Powell den Alltagsrassismus öffentlichkeitswirksam massentauglich und nicht wenige Skinheads folgten seinen Ansichten. ${ }^{60}$ So war der Wahlkampf von Margharet Thatcher ebenfalls von xenophoben und rassistischen Elementen gekennzeichnet, ${ }^{61}$ wahrscheinlich aber auch deswegen, um den Rechtsextremen das Wasser abzugraben. Mit Gramsci gesprochen wurden hier ideologische Zugeständnisse gemacht, um mit der extremen Rechten einen gewissen Konsens zu erreichen:

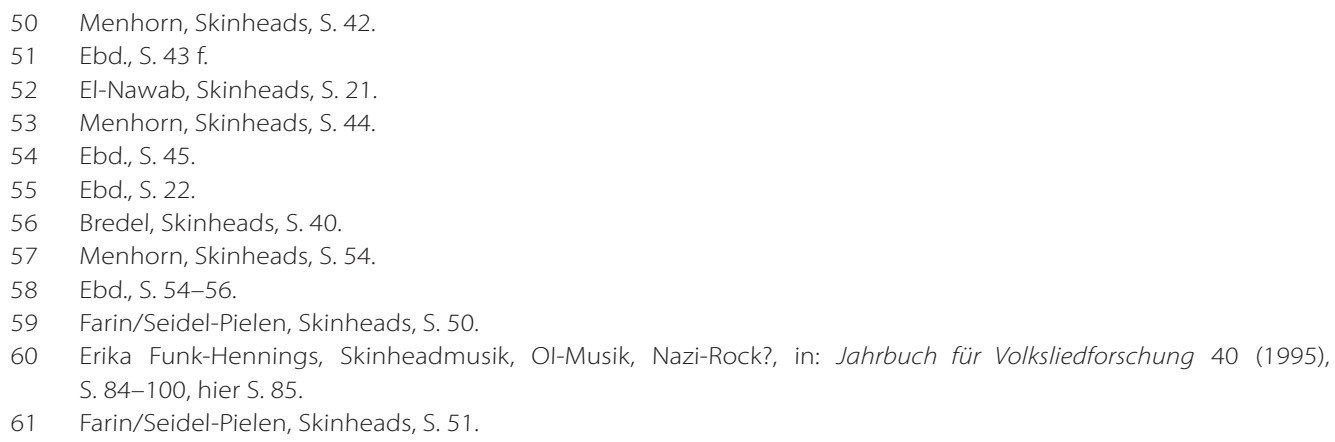


„Wenn [...] [die Regierenden] nicht den Konsens der Mehrheit haben, werden sie als untauglich zu verurteilen sein und als nicht die,nationalen' Interessen vertretend, die dabei, die Willen eher in die eine als in eine andere Richtung zu lenken, vorrangig sein müssen."62

Die NF profitierte dennoch und gab als einzige Partei den Skins das Gefühl, gehört zu werden. ${ }^{63}$ Das stieß auf Gegenliebe, denn mit den faschistischen Parolen der NF wussten sie die Gesellschaft zu provozieren. ${ }^{64}$ Der diffuse Hass auf andere Minderheiten und auf die bürgerliche Gesellschaft wurde so nach und nach in ideologische Bahnen kanalisiert. Die NF erkannte schnell, dass sich Musik bestens zum Transport ihrer Ideologien eignete und so kam es zu einer Zusammenarbeit. ${ }^{65}$

Bald aber spalteten sich die rechtsextremen Skinheadbands von der National Front ab und gründeten unter anderem die international und neonazistisch ausgerichteten Netzwerke "Blood \& Honour" (B\&H) und "Combat 18".66 Das B\&H-Netzwerk schuf der rechtsextremen Skinhead-Bandszene erstmals organisatorische Strukturen. In dessen Logo - einer Triskele, die an das Hakenkreuz angelehnt ist - wird sofort klar, wohin die Richtung gehen sollte. ${ }^{67}$ Die Organisation geht auf lan Stuart Donaldson (genannt lan Stuart) zurück, den Begründer und Sänger von Skrewdriver - nach wie vor einer der legendärsten Neonazibands. ${ }^{68}$ In den Liedern wird eindeutig rassistisches und nationalistisches Gedankengut propagiert, so lautete z.B. im Jahr 1988 der Refrain von „Win or Die“ aus dem Album „After the Fire“" „Fight for your country, fight for your race, fight for your nation, fight made our nation great."69 Die Musik von Skrewdriver ist einfach gehalten und eingängig. Stuart hatte ein gewisses musikalisches Talent, denn Lemmy Kilmister, Sänger der Band Motörhead, äußerte sich 2008 in einem Interview folgendermaßen über Stuart: „I thought lan Stuart should have grown his hair long and there would have been six rolling stones [sic!]!"70 Dadurch und mit seiner Fähigkeit, Netzwerke zu knüpfen, avancierte er im Laufe der Zeit zur Ikone der rechtsextremen Szene. Seit seinem Unfalltod im Jahr 1994 gilt er endgültig als Märtyrer. ${ }^{71}$ In Gramscis Sinne war Stuart einer der Intellektuellen, dem es gelang, innerhalb der Skinheadkultur "als Konstrukteur, Organisator, ,dauerhaft Überzeugender', weil nicht bloßer Redner",72 große Teile davon auf seine Seite zu ziehen. Mit ein Grund dafür war sicherlich das fremdenfeindliche Klima innerhalb der britischen Gesellschaft, d.h. es gab bestimmte Überschneidungen zwischen den neofaschistischen Gruppierungen und der öffentlichen Meinung.

\footnotetext{
62 Antonio Gramsci, Gefängnishefte. Kritische Gesamtausgabe, Hefte 8 und 9, Bd. 5, Hamburg 22012, S. 1126.

63 Farin/Seidel-Pielen, Skinheads, S. 52.

64 Ebd.

65 Menhorn, Skinheads, S. 56

66 Bredel, Skinheads, S. 44.

67 Blood \& Honour, Home, O. D., [http://www.bloodandhonour.net/index.html], eingesehen 12.1.2015.

68 Funk-Hennings, Skinheadmusik, Ol-Musik, S. 87.

69 Youtube LLC, Max Gaozza, SkrewDriver - Win Or Die, 13.6.2013, [https://www.youtube.com/watch?v=OQ2fzKh tuWY], eingesehen 7.1.2015.

70 Blog: Metal Hall eZine, Elric, Lemmy Answers Your Questions, 17.4.2008, [http://metalhall.blogspot.co.at/2008/04/ lemmy-answers-your-questions.html], eingesehen 9.1.2015.

71 Enno Stiehm, Rechtsextreme Jugendliche. Erkennungsmerkmale, Begriffe, Erklärungsansätze und schulische Handlungsmöglichkeiten, Hamburg 2012, S. 51.

72 Antonio Gramsci, Gefängnishefte. Kritische Gesamtausgabe, Hefte 12 bis 15, Bd. 7, Hamburg 22012, S. 1532.
} 
Nach einigen heftigen Ausschreitungen und Übergriffen rechtsextremer Skinheads, die von den Medien gnadenlos ausgeschlachtet wurden, „wusste jeder, wie Nazis aussehen und wie man aussehen muss, wenn man ein rechter Schläger sein will"73 Das zog wiederum rechtsextrem eingestellte Jugendliche an, das harte und martialische Image der Skinheads ergänzte deren Ideologie perfekt. George Marshall, selbst Skinhead der ersten Generation, stellte fest: "The truth was that it wasn't so much skinheads turning to Nazism, but Nazis turning into skinheads." ${ }^{74}$ In diesem Sinne hatte der rechtsextreme Teil der Skinheads - ausgehend von den großen Städten Englands - Anfang der 1980er-Jahre die Hegemonie innerhalb der Szene auf der britischen Insel erreicht, zumal die unpolitischen Skins es nicht vermochten, eine Gegenhegemonie in der öffentlichen Meinung aufzubauen. Deshalb ist es nicht verwunderlich, dass sich "Skinhead" als Synonym für "Neonazi" in das kollektive Bewusstsein gebrannt hat. Dieses Image wurden sie bis heute nicht mehr los. Das zum Teil rechtsextrem eingefärbte Bild wurde anschließend weltweit exportiert, auch nach Deutschland, was in den folgenden Kapiteln in den Mittelpunkt rückt.

\section{Skinheads in der Bundesrepublik}

In der Blütezeit der Oi!-Bewegung erreichte der Skinheadkult internationale Bekanntheit. In Westdeutschland vor allem durch englische Musikzeitschriften und Skinheads, die den dort stationierten britischen Truppen angehörten. ${ }^{75}$ Die ersten Skins rekrutierten sich ab ca. 1980 sowohl aus der Punk- als auch aus der Hooliganszene. ${ }^{76}$ Obwohl viele Skins und Punks sich anfangs durchaus freundlich gegenüberstanden, kam es durch simple Verallgemeinerungen spätestens im Rahmen der Ausschreitungen bei den Chaostagen 1984 in Hannover77 zum Bruch zwischen beiden Subkulturen. Skins kritisierten den zunehmend linken Einfluss auf die Punkszene, Punks unterstellten Skinheads pauschal, Faschisten zu sein. ${ }^{78}$ Bis Anfang der neunziger Jahre standen sich die beiden Subkulturen fast unversöhnlich gegenüber. Tatsächlich driftete eine große Anzahl der deutschen Skinheads bald nach rechtsaußen ab, ${ }^{79}$ und das noch bevor sich politische Gruppierungen bedeutend einmischten. Menhorn gibt drei Gründe an, warum es dazu kam: ${ }^{80}$ Erstens wollten sie sich von den Punks klar abgrenzen. Im Gegensatz zu Letzteren waren ihnen Werte wie Ordnung, Pünktlichkeit, Sauberkeit, Kameradschaft und Disziplin wichtig - alles sogenannte deutsche Werte. Zweitens wollten auch sie wie die Punks mit Tabubrüchen Aufsehen erregen. Mit ihrem Aussehen konnten sie die Gesellschaft kaum noch schockieren, dafür griffen sie auf nationalsozialistischen Parolen zurück. War das anfangs nur als Provokation gedacht, wurde das Gedankengut dann häufig übernommen. Drittens spielte die unreflektierte Englandorientierung eine

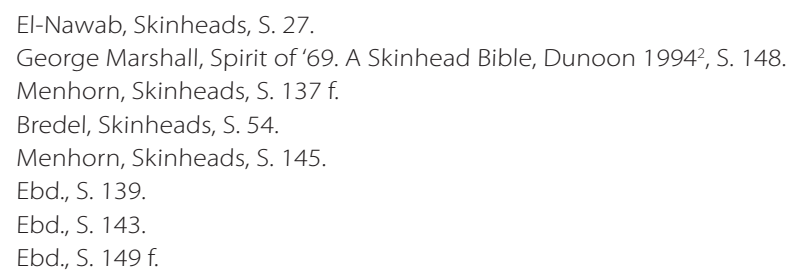


große Rolle. Skrewdriver war von Anfang an eine Kultband und - wie noch ausgeführt werden wird - diese Rolle nahmen wenig später die Böhsen Onkelz ein.

Schon bald erkannten neonazistische Gruppen das Potential dieser Subkultur. Kurz nach dem Auftauchen der ersten Skins in Deutschland bemühte sich der Neonazi Michael Kühnen im Rahmen seiner Aktionsfront Nationaler Sozialisten um Skinheads, die er vor allem in Fußballstadien und Konzerten fand. ${ }^{81}$ Der Hass auf Ausländer und Linke sowie die Akzeptanz von Gewalt machte sie zu Verbündeten. Doch nach anfänglichen Erfolgen wendeten sich die meisten Skinheads wieder ab. Sie lehnten fest organisierte Strukturen $a b^{82}$ und wollten sich von den Neonazis nicht mehr als Schlägertrupps benutzen $^{83}$ lassen. Das mag vielleicht auch daran liegen, dass ihnen die ursprünglichen Werte der Subkultur noch eher bekannt waren als der darauf folgenden Skingeneration. Und auch wenn sie viele gemeinsame Schnittpunkte hatten - sie waren eher an konkreten Aktionen interessiert als an organisierter Parteienarbeit. ${ }^{84}$ Das verhinderte nicht, dass sich die Gewalt gegen die verhassten Gruppen hochschaukelte: Ab Mitte der achtziger Jahre wurde die Mehrzahl an rechtsextrem motivierten Gewalttaten von Skinheads ausgeführt, bis dahin führten neonazistische Gruppierungen diese unrühmliche Statistik an. ${ }^{85}$ Das hängt damit zusammen, dass sich die Skinheadszene von nun an bedeutend änderte: Von den sich neu rekrutierenden Skinheads stammten etliche aus Neonazikreisen. Neue Bands mit klar neonazistisch durchzogenen Texten schossen aus dem Boden und folglich fiel es viel leichter, sich Parteien und organisierten Gruppierungen anzuschließen bzw. anzunähern. ${ }^{86}$ Viele Skinheads der älteren Generation ${ }^{87}$ und aus der unpolitischen Szene ${ }^{88}$ trugen diese Entwicklungen nicht mehr mit und stiegen aus. Die beharrliche Agitationsarbeit von Neonazis zahlte sich damit auf lange Sicht aus - die rechtsextremen Skins beherrschten erstmals das Feld innerhalb der Szene. ${ }^{89}$ Die Grenzen zwischen Subkultur und Ideologie verschwammen bis Ende der 1980er-Jahre zusehends. ${ }^{90}$

\section{Skinheads in der DDR}

Auch die Berliner Mauer hielt den Skinheadkult nicht davon ab, in die DDR einzudringen. Die ersten Skins rekrutierten sich Anfang der 1980er vor allem aus der Hooliganszene, aber auch Punks fanden Gefallen an der Subkultur. ${ }^{91}$ Das geschah unter starkem Einfluss der westdeutschen Szene, es gab reichlich Kontakte, z.B. bei Fußballspielen

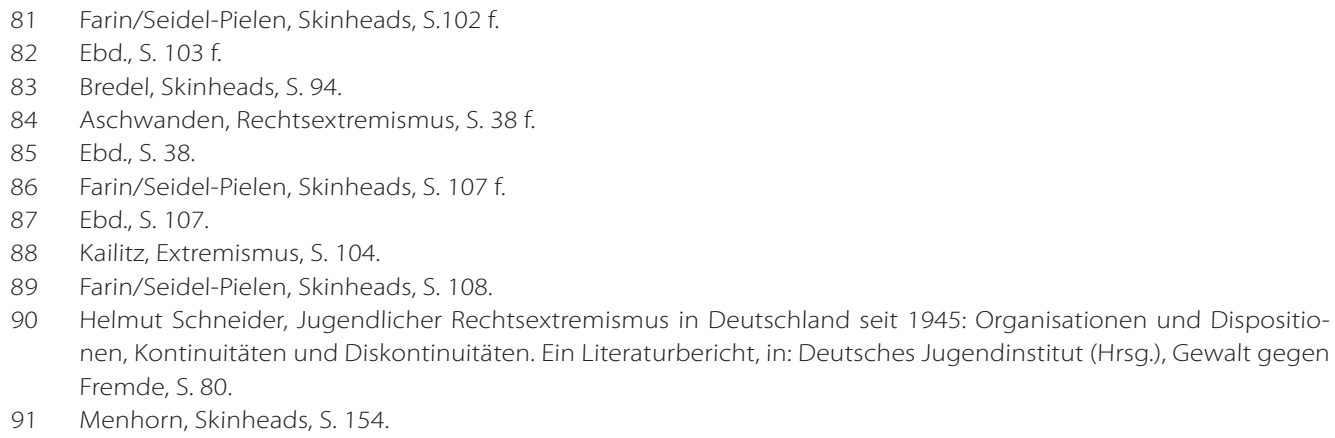


oder Skinheadkonzerten in anderen Ländern hinter dem Eisernen Vorhang. ${ }^{92}$ Gewalt, Spaß, Alkohol und Kameradschaft gehörten natürlich auch im Osten zum Skinheaddasein. Doch es gab einige Unterschiede zu den westdeutschen Pendants, was auch den bis heute stärkeren Politisierungsgrad der Skinheads in der ehemaligen DDR erklärt: Erstens fiel schon eine starke Ablehnung gegen staatliche Institutionen und insbesondere gegen das sozialistische System auf, d.h. die Tendenz zeigte von Grund auf nach rechts. ${ }^{93}$ Und womit könnte man das SED-Regime besser ärgern und zugleich eine extreme Position der Opposition ausdrücken als mit neonazistischen Parolen? Zweitens waren die westdeutschen Kontaktpersonen meist rechtsextreme Skinheads und auch im Osten waren die Kultbands Skrewdriver und die Böhsen Onkelz. ${ }^{94}$ Drittens suggerierten die Medien beider deutscher Staaten das Bild, es gebe ausschließlich rechtsextreme Skinheads. ${ }^{95}$ Dennoch gab es hier eine Unterschied, da es in Westdeutschland wesentlich mehr Informationskanäle und Verbindungen nach England gab, etwa durch Fanzines. Die Skinheadkultur kam im Westen in einem relativ breiten Spektrum an, in der DDR war sie hingegen von Anfang an mit rechtsextremer Ideologie angereichert. Das hatte zur Folge, dass - im Gegensatz zur ersten Skingeneration der BRD - ostdeutsche Skins keinen Bezug zu den multikulturellen Wurzeln der Subkultur hatten.

Die DDR-Führung ignorierte die Aktivitäten von Skinheads lange Zeit, wo es doch hinter dem antifaschistischen Schutzwall - zumindest offiziell - keinen Faschismus gab. ${ }^{96}$ Soziale Ungleichheit in der sozialistischen DDR war ideologisch undenkbar. Damit wurde eine hinreichende Aufarbeitung des Nationalsozialismus erheblich erschwert bzw. unmöglich gemacht. Von Amts wegen war die ostdeutsche Geschichte unbefleckt, andererseits war eine erhebliche Anzahl von ehemaligen Nazis niedrigen Ranges in den Staatsapparat integriert worden. ${ }^{97}$ Diese Doppelmoral bzw. Diskrepanz zwischen staatlicher Verordnung und Realität spiegelt sich etwa auch bei der Behandlung von fremden Gastarbeitern wider. Sie wurden - neben vielen anderen Diskriminierungen - hauptsächlich für unliebsame Arbeiten bei niedriger Bezahlung eingesetzt, dazu noch privat als auch in der Arbeit von der restlichen Bevölkerung isoliert und in ihren Rechten erheblich eingeschränkt. ${ }^{98}$ Eine derartige Praxis wurde für viele DDR-Bürger aufgrund der Alltagserfahrungen gesellschaftsfähig. So hatten Ausländer z.B. bei den vielen Güterengpässen der DDR eine Sündenbockfunktion. ${ }^{99}$ Der ideologische Nährboden für ausländerfeindliche Einstellungen war also zu einem guten Teil, hausgemacht'. Im Verlauf der 1980er-Jahre gingen die Provokationen dann in handfeste Denkmuster über. Dabei kam es analog zu Westdeutschland ab Mitte des Jahrzehnts vermehrt zu

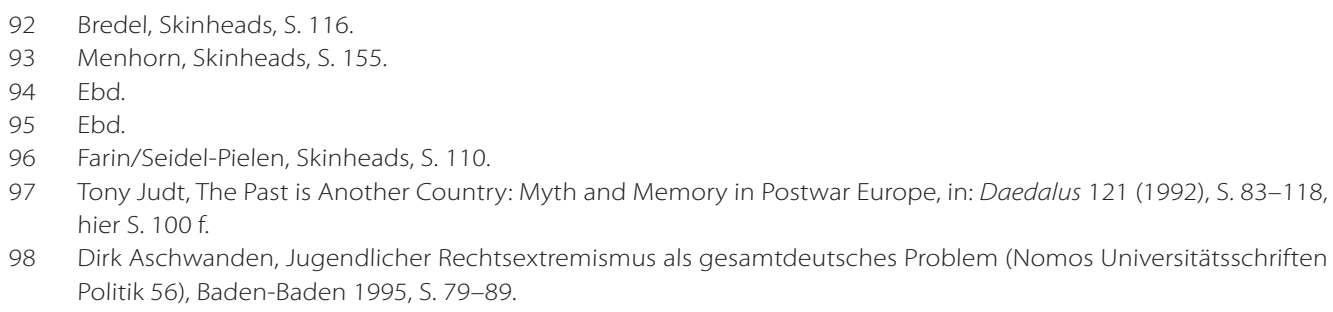


Übergriffen auf ausländische Minderheiten. ${ }^{100}$ Während aber der Skinheadkult in der BRD nur teilweise politisch aufgeladen ankam, so stand dieser im Osten Deutschlands von Anfang an unter rechtsextremen Vorzeichen. Für Neonazis herrschten also "gute Voraussetzungen" im Hinblick auf die Wiedervereinigung.

\section{Nach dem Mauerfall}

Mit dem Fall der Mauer boomte die Skinheadszene, vor allem in den neuen Bundesländern. ${ }^{101}$ Dementsprechend stieg auch die Anzahl rechtsextremer Gewalttaten im nun vereinten Deutschland. Ihren Gipfel erreichten sie mit knapp 1.500 Gewaltdelikten im Jahr 1992, das ist in etwa der neunfache Wert im Vergleich zu 1990. ${ }^{102}$ Traurige Höhepunkte waren die Brandanschläge auf Asylwerberheime Anfang der 1990er in Hoyerswerda, Rostock und Mölln mit vielen Verletzten und mehreren Toten. ${ }^{103}$ Die Politik reagierte nun mit zahlreichen Verboten von neonazistischen Organisationen und Parteien, deren Gegenreaktion ließ allerdings nicht lange auf sich warten: Um zukünftigen Verboten zu entgehen, schlossen sie sich jenseits der NPD zu losen Verbindungen, den Kameradschaften, zusammen, womit sie strukturell den Zusammenschlüssen von Skinheads ähnelten. ${ }^{104}$ Von nun an vertiefte sich die Zusammenarbeit der beiden Szenen - es bildete sich eine Art Symbiose. ${ }^{105}$ Sowohl die Organisation von Skinheadkonzerten durch Neonazis sowie die Mitgliedschaft von Neonazis in Skinheadbands hatten großen Anteil an dieser Annäherung. ${ }^{106}$ Jetzt begann auch die NPD, sich der Jugend zu öffnen - nicht zuletzt deswegen, weil sie eine,Verjüngungskur' brauchte. Während die Skinheads der damals biederen und national-konservativen NPD Mitte der 1980er zu undiszipliniert waren ${ }^{107}$ und die Skinheads nichts von Parteien hielten, kamen nun beide Seiten aufeinander zu. Die Kontakte zur NPD wurden auch deshalb erleichtert, da sich Mitglieder der Kameradschaftsszene nach der angesprochenen Verbotswelle bei den Jungen Nationaldemokraten (JN) engagierten und dort Führungspositionen einnahmen. ${ }^{108}$

Fortan waren Skinheads häufig bei NPD-Kundgebungen und als Helfer bei Wahlkampfveranstaltungen zu sehen, die JN organisierte im Gegenzug Rechtsrockkonzerte. ${ }^{109} \mathrm{Ei}$ nen entscheidenden Impuls gab die Übernahme des Parteivorsitzes durch Udo Voigt im Jahr 1996. ${ }^{110}$ Mit ihm änderte sich sie Strategie, es wurde ein Drei-Säulen-Konzept eingeführt und das lautete: Kampf um die Köpfe - Kampf um die Straße - Kampf um

\footnotetext{
100 Bredel, Skinheads, S. 112.

101 Menhorn, Skinheads, S. 160-162.

102 Kailitz, Extremismus, S. $104 \mathrm{f}$.

103 Ebd.

104 Bredel, Skinheads, S. 96.

105 Ebd.

106 Ebd.

107 Martin Langebach/Jan Raabe, Zwischen Freizeit, Politik und Partei: Rechtsrock, in: Stephan Braun/Alexander Geisler/Martin Gerster (Hrsg.), Strategien der extremen Rechten. Hintergründe - Analysen - Antworten, Wiesbaden 2009, S. 163-188, hier S. 164.

108 Bredel, Skinheads, S. 98.

109 Ebd., S. $97 \mathrm{f}$.

110 Langebach/Raabe, Freizeit, S. 166.
} 
die Parlamente. ${ }^{11}$ Mit dem Kampf um den organisierten Willen wurde dieses Modell um eine vierte Säule erweitert: Alle nationalen Kräfte sollten gebündelt werden. ${ }^{112}$ Die Skins beteiligten sich hauptsächlich am Kampf um die Straße - und wurden dabei immer disziplinierter. Die NPD organisierte 1997 in München eine Großdemonstration von etwa 5.000 Personen gegen die Ausstellung zu den Verbrechen der Wehrmacht. Zahlreiche Skinheads marschierten mit, die sich auffallend ruhig verhielten und sich der Partei unterordneten. ${ }^{113}$

Die subkulturellen Werte schienen zu diesem Zeitpunkt keine Rolle mehr zu spielen. Die NPD wurde moderner, jünger und bot der jugendlichen Generation eine Erlebniswelt. Der aktionsorientierte Aspekt stand dabei sicherlich im Vordergrund, die beiläufige, aber intentionale Vermittlung der Ideologie war somit um Vieles leichter. Davon blieb auch die Musik nicht verschont, der Rechtsrock diente der NPD als wichtige und wirkungsvolle Propagandawaffe, z.B. auch bei Parteiveranstaltungen. Paradoxerweise waren es gerade die oben erwähnten Verbote, die die Allianz zwischen Kameradschaften, Skinheads und rechtsextremen Parteien erst möglich machte. Die Skinheads boten ein großes Rekrutierungs- und Instrumentalisierungspotential für die NPD und diese war dabei erfolgreich, das Potential auszuschöpfen. In den letzten Jahren ist der Anteil der Skinheads rückläufig: Zu schlecht ist deren Ruf, zu offensichtlich wird die Gesinnung zur Schau gestellt und zu antiquiert ist es mittlerweile, Skinhead zu sein. Zudem war und ist der Anteil der Skins über dreißig Jahren marginal und lag im unteren einstelligen Prozentbereich. ${ }^{114}$ Das konnte vielfältige Gründe haben, etwa eine bröckelnde Identifikation mit der Szene aufgrund der zunehmenden Politisierung. Offenbar war dies aber auch dem Alter geschuldet, auch Faktoren wie Arbeit, Familie oder Kinder waren gewichtige Beweggründe für den Ausstieg aus der Szene. ${ }^{115}$ Das konnte zwar für jüngere Skins ebenso gelten, dennoch lassen diese Aspekte im Zusammenhang mit der Altersstruktur darauf schließen, dass zahlreiche ältere Skins beschlossen, ein sogenanntes,normales' Leben zu führen. An die Stelle der rechtsextremen Skinheads sind nun die AN getreten, die nicht minder gewalttätig sind. Die Botschaften sind die gleichen, nur die Vermittlung erfolgt subtiler, moderner und professioneller. Bevor die AN behandelt werden, soll berechtigterweise ein Blick auf die Gegenbewegungen innerhalb der Skinheadszene geworfen werden.

\footnotetext{
111 Armin Pfahl-Traughber, Der „zweite Frühling” der NPD. Entwicklung, Ideologie, Organisation und Strategie einer rechtsextremistischen Partei, Berlin 2008, S. 42-45, [http://www.kas.de/wf/doc/kas_14498-544-1-30.pdf], eingesehen 12.1.2015.

112 Ebd., S. 45-47.

113 Bredel, Skinheads, S. 97.

114 Ebd., S. 68

115 Ebd., S. 70
} 
Gegenbewegungen

In der deutschen Öffentlichkeit ist das Wort Skinhead spätestens seit der Gewaltwelle Anfang der 1990er zum Synonym für Neonazi geworden. Die Medien dürfen dabei nicht außer Acht gelassen werden, denn sie spielten eine entscheidende Rolle. Im Sinne von Gramsci, der der Presse schon eine herausragende Rolle zuschrieb, trugen die Medien - sei es aus Profit- und/oder Sensationsgier - zu einem bedeutenden Teil dazu bei, dass Skinheads allesamt als rechtsextrem kategorisiert wurden. Obwohl das auf einen beträchtlichen Teil zutrifft, formierte sich in den folgenden Jahren - als die Skinheadkultur schon internationalisiert war - Widerstand. Neben den rechtsextremen Skins mit deutlich neonazistischen Tendenzen spaltete sich die Skinheadszene in folgende Strömungen auf: ${ }^{116}$ Die Oi!-Skins definieren sich als unpolitisch und versuchen, an die Ideale der ersten Skinheadgeneration anzuschließen, also Bier, Spaß, Musik, Fußball usw. S.H.A.R.P-Skins ${ }^{117}$ distanzieren sich ausdrücklich von Ausländerfeindlichkeit und Rassismus, um nicht mit rechtsextremen Skins in einen Topf geworfen zu werden. Als Gegenpol zu den rechtsextremen Skins formierten sich die Redskins, die politisch auf der linken bis linksextremen Seite agieren. Der äußerliche Unterschied zwischen den einzelnen Skingruppierungen liegt im Detail und ist etwa durch Aufnäher, Buttons oderT-Shirts zu erkennen. Es bleibt festzuhalten, dass die Skinheadkultur in Wirklichkeit sehr heterogen ist und nicht nur auf rechtsextreme Schläger reduziert werden kann, wie es die Medien gerne suggerieren. Die restlichen Strömungen wurden aber in den Medien praktisch kaum wahrgenommen. ${ }^{118}$

\section{Autonome Nationalisten}

„Vergessen Sie die Springerstiefel, bitte!", 119 so lautet der erste Satz im journalistischen Werk „Neue Nazis" von Toralf Staud und Johannes Radke. Der Modernisierungsprozess erfasste auch den Rechtsextremismus. Analog zur rechtsextremen Musik erfolgte hier ein Prozess der Ausdifferenzierung. Ein Resultat dessen ist die Entstehung der AN, die auf den ersten Blick von Linksautonomen nicht zu unterscheiden sind.

\section{Entstehung}

Die Freien Kameradschaften, die große Teile der rechtsextremen Skinheads an sich binden konnten, sind jene Keimzelle und Vorstufe, aus der die AN entstanden sind. Mediale Aufmerksamkeit erweckten sie in Deutschland erstmals anlässlich gewalttätiger Ausschreitungen im Jahr 2008 bei einem Aufmarsch zum ersten Mai in Hamburg. ${ }^{120}$

116 Bredel, Skinheads, S. 85-93.

117 Abkürzung für: Skinheads Against Racial Prejudice.

118 Bredel, Skinheads, S. 9.

119 Toralf Staud/Johannes Radke, Neue Nazis. Jenseits der NPD: Populisten, Autonome Nationalisten und der Terror von Rechts, Köln 2012², S. 7.

120 Lenard Suermann, Rebel Without a Course. Der Diskurs um die „Autonomen Nationalisten", in: Regina Wamper/ Helmut Kellershohn/Martin Dietzsch (Hrsg.), Rechte Diskurspiraterien. Strategien der Aneignung linker Codes, Symbole und Aktionsformen, Münster 2010, S. 166-193, hier S. 166. 
Doch die ersten AN rekrutierten sich bereits 2002 aus der Berliner Kameradschaft Tor, ${ }^{121}$ die unter anderem durch Hausbesetzungen ${ }^{122}$ auffielen. Durch den Umstand, dass in den neuen Bundesländern rechtsextreme Strukturen salonfähiger waren als in den alten, agierten die AN lange hauptsächlich im Westen, jedoch sympathisierten immer mehr Freie Kameradschaften im Osten mit den AN. ${ }^{123}$ Dennoch kam es dort zu keiner größeren Ausbreitung der AN: Die NPD war in den neuen Bundesländern tiefer in der Gesellschaft verankert als im Westen und damit auch die Freien Kameradschaften, die ihren relativ gefestigten Status nicht durch rebellische und antibürgerliche Aktionen riskieren wollten. ${ }^{124}$ Der Altersdurchschnitt lag zwischen 15 und 20, bei Führungsaktivisten zwischen 18 und 25 Jahren, womit sie durchschnittlich jünger als die Mitglieder der Freien Kameradschaften waren. ${ }^{125}$ Das ist durchaus als Indiz für einen Generationswechsel zu deuten, der die dazugehörigen Konflikte mit sich brachte. Sie kritisierten die NPD als reformistisch und reaktionär, sie wollten durch eine Revolution und nicht auf legalistische Weise an die Macht kommen. ${ }^{126}$ Den Freien Kameradschaften warfen sie vor, sich dem Neuen zu verschließen. ${ }^{127}$

Neu ist aber auch das Konzept des autonomen Nationalismus nicht, ganz bewusst wurden die Linksautonomen kopiert. Sie machen auch kein großes Geheimnis daraus, bezeichnenderweise schrieb der den AN sehr nahe stehende Neonazi Christian Worch: „Bevor ich das Rad neu erfinde, schaue ich mir an, ob irgendwo ein Rad läuft; dann schaue ich mir das Rad an und überlege, ob es für unsere Zwecke geeignet ist."128 Von den Linken zu lernen erachte er daher als "höchst sinnvoll“.129 In ähnlicher Weise äußern sich die AN Vorderpfalz: „Die Linke macht dies seit langem erfolgreich vor, nun liegt es an uns, selbiges Konzept aufzugreifen."130 Innerhalb des rechtsextremen Spektrums kam es - ähnlich wie anfangs bei den Skinheads und vor allem als die ersten AN auftauchten - zu Widerständen und Anfeindungen. Eine Erklärung des NPD-Parteipräsidiums aus dem Jahr 2007 fiel dementsprechend aus, indem die Partei sich „in aller Deutlichkeit gegen derartige anarchistische Erscheinungsformen aus[sprach]". ${ }^{131}$ Da sich daraufhin viele aus der rechtsextremen Szene mit den AN solidarisch erklärten, wurde diese Haltung von der NPD bald relativiert: Etwa einen Monat später begrüßte Udo Voigt anlässlich einer Wahlkampfveranstaltung zur Landtagswahl in Niedersach-

121 Jan Schedler, Übernahme von Ästhetik und Aktionsformen der radikalen Linken - Zur Verortung der „Autonomen Nationalisten" im extrem rechten Strategiespektrum, in: Stephan Braun/Alexander Geisler/Martin Gerster (Hrsg.), Strategien der extremen Rechten. Hintergründe - Analysen - Antworten, Wiesbaden 2009, S. 332-357, hier S. 334.

122 Regina Wamper/Michael Sturm/Alexander Häusler, Faschistischer Selbstbedienungsladen? Aneignungspraktiken der ,Autonomen Nationalisten' in historischer und diskursanalytischer Perspektive, in: Jan Schedler/Alexander Häusler (Hrsg.) Autonome Nationalisten. Neonazis in Bewegung, Wiesbaden 2011, S. 284-302, hier S. 298. Schedler, Übernahme, S. 337.

124 Ebd.

125 Ebd., S. 336.

126 Ebd., S. 335

127 Ebd.

128 Christian Worch, Über freien und autonomen Nationalismus, 25.1.2005, [http://web.archive.org/web/200702280 45353/http://1 mai.net//, eingesehen 15.2.2015.

129 Ebd.

130 Blog: Autonome Nationalisten Vorderpfalz, Warum Autonom?, o. D., [http://logr.org/autonomenationalistenvorderpfalz/was-wir-wollen/warum-autonom/], eingesehen 15.2.2015.

131 NPD-Parteipräsidium, Unsere Fahnen sind schwarz - unsere Blöcke nicht!, (15.8.)2007, S. 1, [http://www.npd-kiel. de/Archiv/2007/PDF_Dateien/Akt_Aufruf_PV.pdf], eingesehen 15.2.2015. 
sen ausdrücklich etwa hundert Autonome Nationalisten ${ }^{132}$ - das Bündeln aller nationalen Kräfte, die vierte Säule der NPD, kommt zum Tragen. Es könnte sinngemäß auch so formuliert werden:

„Wenn die Bauern sich bewegen, beginnen die Intellektuellen zu schwanken, und umgekehrt, wenn eine Gruppe Intellektueller sich auf die neue Grundlage stellt, reißt sie schließlich immer größere Teile der Masse mit."133

\section{Strategien, Aktionsformen und Symbolik}

„Wir versuchen einen neuen Weg, der sich wahlpolitischer Träume weitgehend enthält, auf einen kontinuierlichen Aufbau setzt und der Gegenseite möglichst geringe Angriffsflächen bietet, um außerhalb der Parlamente eine kräftige Gegenmacht zu entwickeln, die in geeigneter Stunde eingreift."134

Diese Aussage beinhaltet viel von Gramscis Hegemonietheorie, nur eben mit rechtsextremem Hintergrund. Das deckt sich ebenfalls mit seiner Aussage, dass „[man] im politischen Kampf [...] nicht die Kampfmethoden der herrschenden Klasse nachäffen [darf], oder man gerät leicht in einem Hinterhalt".135 In diesem Sinne sind die AN als Ganzes in lose Gruppen ohne feste Organisationen zersplittert, dennoch sind sie durch die modernen Kommunikationsmedien - vor allem durch das Internet - vernetzt. Das macht sie für staatliche Verfolgungsbehörden schwer greifbar, kaum eine dem rechtsautonomen Spektrum zugehörige Gruppierung ist auf der Liste der verbotenen Organisationen. ${ }^{136}$ Anders als bei den Linksautonomen ist diese lose Struktur bzw. die Ablehnung des Führerprinzips nicht weltanschaulich bedingt, sondern strategischer und taktischer Natur. ${ }^{137}$ Diese Autonomie wirkte sich auch auf das Erscheinungsbild der Aktivisten aus: Anders als noch bei den Skinheads besteht kein Dresscode; Kapuzenpullover, Baseballcaps und lange Haare sind keine Seltenheit: „Auf was für Klamotten du stehst oder wie du deine Haare gern trägst, ist für den politischen Kampf nicht von Bedeutung."138 Auf dieser Grundlage ist es für rechtsorientierte Jugendliche attraktiver als in Parteien oder Kameradschaften, selbst aktiv zu werden. Das häufig in Subkulturen vorkommende Do-lt-Yourself-Prinzip (z. B. Plakate, Aufkleber) wird aufgegriffen, um den Rechtsextremismus in einer dem Mainstream entgegengesetzten und rebellischen Art

132 Tomas Sager, Freund oder Feind? Das widersprüchliche Verhältnis von ,Autonomen Nationalisten', NPD und neonazistischer Kameradschaftsszene, in: Schedler/Häusler (Hrsg.), Autonome Nationalisten, S. 105-120, hier S. 110.

133 Gramsci, Gefängnishefte 1, S. 109.

134 Altermedia Deutschland, Wie organisieren wir den Widerstand, 21.10.2012, [http://altermedia-deutschland.info/ content.php/2413-Wie-organisieren-wir-den-Widerstand], eingesehen 15.2.2015.

135 Gramsci, Gefängnishefte 1, S. 177.

136 Bundesamt für Verfassungsschutz, Rechtsextremismus: Symbole, Zeichen und verbotene Organisationen, o. D. (2014), [http://www.verfassungsschutz.de/embed/broschere-2014-03-rechtsextremismus-symbole-zeichen-und -verbotene-organisationen.pdf], eingesehen 19.2.2015.

137 Baron, Selbstverständnis, S. 442 f.

138 Internet Archive, Autonome Nationalisten - Wolfenbüttel/Salzgitter, 26.2.2013, [http://web.archive.org/web/ 20130226203436/http://www.an-wfsz.info/?page_id=1771], eingesehen 19.2.2015. 
vor allem Jugendlichen schmackhaft zu machen. Sie propagieren „ein Konzept des politischen Partisanen, welcher sich anonym in der Gesellschaft bewegt".139

Die AN verbreitern somit das rechtsextreme Angebot mit einem jugendaffinen und modernen Anstrich, die Ideologie ist dennoch deutlich rückwärtsgewandt. Ideologisch beziehen sie sich auf die Nationalrevolutionäre der 1920er- und 1930er-Jahre, auf Ernst von Salomon, Ernst Niekisch, die Gebrüder Strasser und den jungen Joseph Goebbels. ${ }^{140}$ Damit greifen sie eher den Linken angeheftete Themen wie Kapitalismusund Globalisierungskritik auf und verbinden sie mit völkisch-nationalistischen Positionen. ${ }^{141}$ "Gegen Staat und Kapital" "Die Globalisierung stoppen“ oder "Für Umwelt-/Tierschutz" lauten z. B. einige ihrer Forderungen. ${ }^{142}$ Obwohl Anglizismen in rechtsextremen Kreisen weiterhin verpönt sind, werden sie von den AN dennoch verwendet: Slogans wie "Fight the system" sowie "Capitalism Kills" wurden eins zu eins übernommen, ${ }^{143}$ "Good Night White Pride" aus der Hardcore/Punk-Szene werden zu "Good Night Left Side".144 Aus der "Antifaschistischen Aktion" wurde "Nationale Sozialisten Bundesweite Aktion" samt der typischen Antifafahne ${ }^{145}$ und sogar das linke Idol Che Guevara wurde für ihre Zwecke instrumentalisiert. ${ }^{146}$ Waren kunstvoll gestaltete Graffiti eher dem linken bzw. alternativen Spektrum zuzuordnen, tauchten in jüngster Zeit auch Graffiti mit neonazistischen Botschaften ${ }^{147}$ auf.

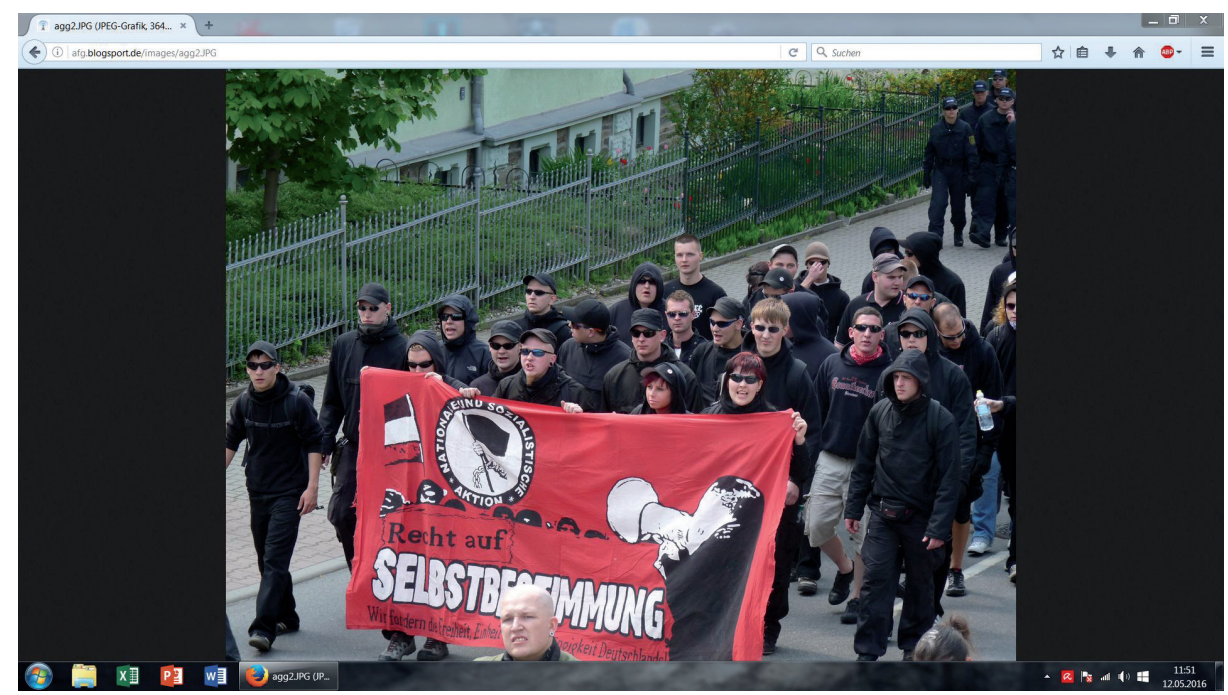

Abbildung 1: Ein rechtsexremer Schwarzer Block

139 Internet Archive, Autonome Nationalisten - Wolfenbuttel/Salzgitter, 26.2.2013, [http://web.archive.org/web/ 20130226203436/http://www.an-wfsz.info/?page_id=1771], eingesehen 19.2.2015.

140 Baron, Selbstverständnis, S. 443

141 Ebd.

142 Blog: Autonome Nationalisten Stormarn, Autonome Nationalisten Stormarn, 30.10.2010, [http://logr.org/anstormarn/], eingesehen 20.2.1015.

143 Baron, Selbstverständnis, S. 446.

144 Suermann, Rebel, S. 444.

145 Wamper/Sturm/Häusler, Selbstbedienungsladen, S. 297.

146 Baron, Selbstverständnis, S. 446

147 Blog: Straßenkunst.info, Startseite, O. D., [http://logr.org/strassenkunst/index.html], eingesehen 21.1.2015. 


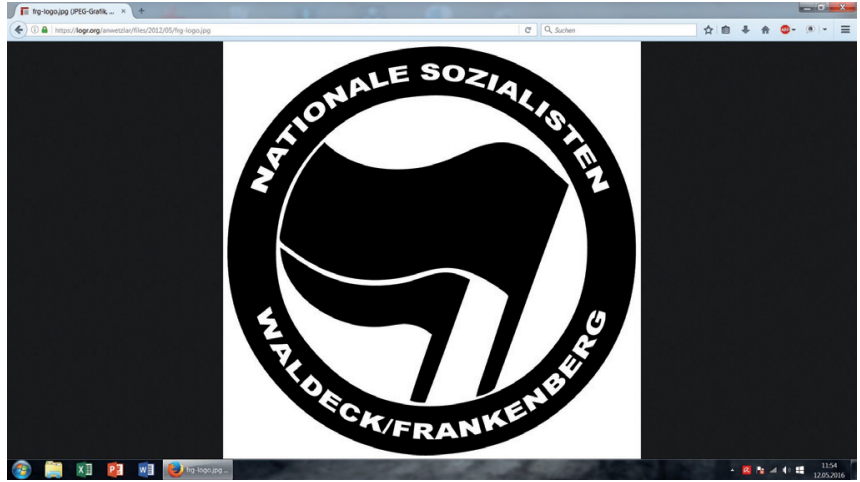

Abbildung 2: Die Aneignung des Antifa-Logos

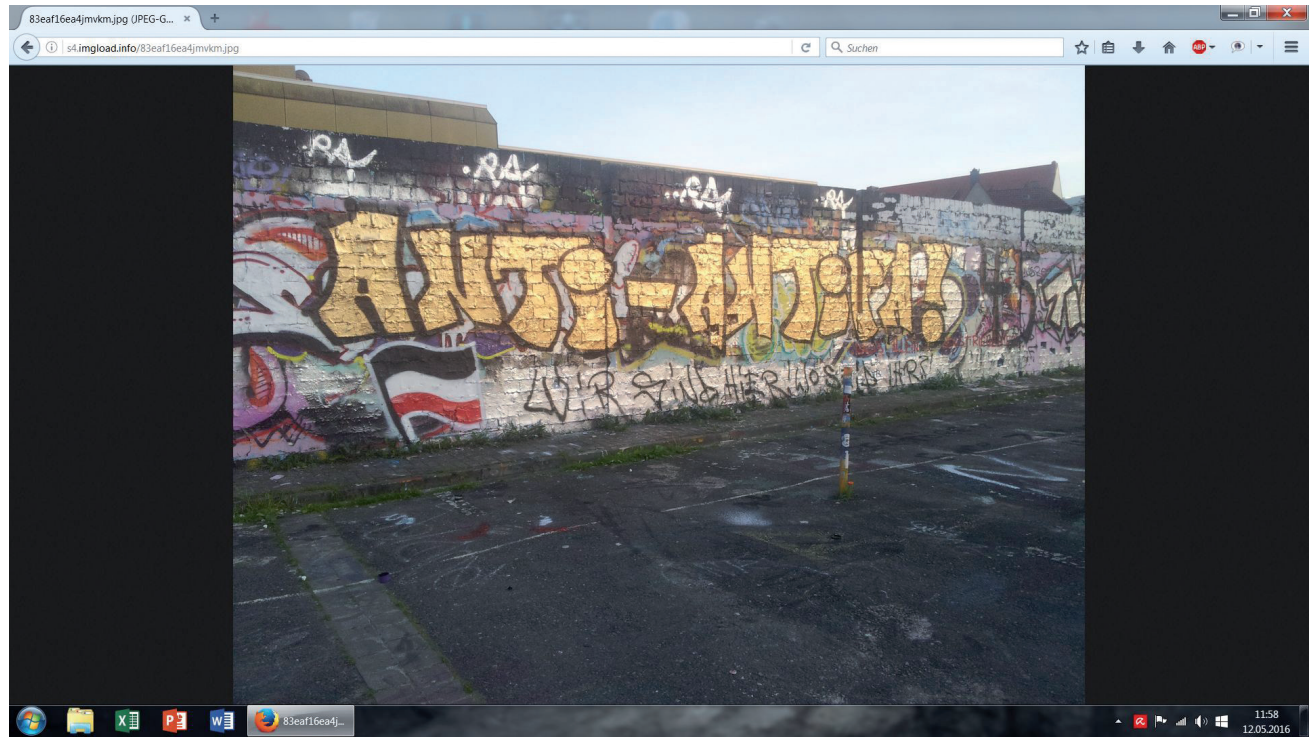

Abbildung 3: Rechtsextremes Graffito in Braunschweig

Nach diesem Schema wird versucht, nahezu die gesamte linke Symbolwelt zu vereinnahmen, sie „schließen an popularisierte Ausdrucksformen an, um hegemoniale Deutungshoheit zu erlangen“. ${ }^{48}$ Dies versuchen sie „indem sie neue Termini einführ[en], bereits gebräuchliche Termini mit neuem Inhalt anreicher[n], Metaphern erschaff[en], sich historischer Namen bedien[en]". ${ }^{49}$ Teilweise wurde versucht, Querfronten mit linksradikalen Aktivisten zu bilden, indem „die positiven Elemente aus der antideutschen Linken und der kapitalistischen Rechten heraus[gebrochen]"150 werden. Nicht umsonst wird häufig das Symbol des nationalrevolutionären Flügels, Hammer mit

148 Wamper/Sturm/Häusler, Selbstbedienungsladen, S. 298.

149 Gramsci, Gefängnishefte 1, S. 92.

150 Autonome Nationalisten Mecklenburg \& Pommern, Wofür trittst du ein? 8 Fragen an einen nationalen Sozialisten, o. D., [http://logr.org/anmup/2013/09/20/wofuer-trittst-du-ein-8-fragen-an-einen-nationalen-sozialisten/], eingesehen 20.2.2015. 
Schwert, verwendet. ${ }^{151}$ Das soll die Einheit zwischen Soldaten und Arbeitern darstellen, denn die AN verstehen sich als politische Soldaten, etwa nach dem Vorbild der SA. Zusammenarbeit in Form einer Querfront als historisches Vorbild gab es z.B. bereits 1932, als die KPD und die NSDAP gemeinsam bei den Berliner Verkehrsbetrieben streikten: Walter Ulbricht und Joseph Goebbels hielten auf derselben Massenkundgebung eine Rede. ${ }^{152}$ In der jüngeren Geschichte kam jedoch eine derartige Zusammenarbeit bis dato noch nicht vor. ${ }^{153}$ Dennoch ist die Übernahme linker Aktionsformen, Begriffe und Symbole für sich gesehen bereits eine Art der Querfrontstrategie. Deutlich wurde dies auch bei der Bildung von Schwarzen Blöcken im Zuge von Demonstrationen nach dem Vorbild von linksextremen Aktivisten, ${ }^{154}$ was die Zuordnung zu einem gewissen Spektrum schwierig macht. Die AN sehen ihren Einsatz von Gewalt gegen ihre Feinde als "sinnvoll“155 an, Linksautonome würden dagegen für ",sinnlose' Gewalt und Zerstörung, meist durch Einfluss von Drogen und Alkohol"156 stehen. Auch auf die Erfahrungen der Gegenseite bei Demonstrationen wird zurückgegriffen: „Die Videos sind zwar von der Antifa, für uns allerdings genauso aktuell."157

Ein weiterer Aspekt ist die sogenannte „Anti-Antifa-Arbeit" bzw. „Feindaufklärung": Aktivitäten von Linken sowie missliebigen Journalisten und Politikern werden dokumentiert und deren Daten gesammelt. „Das Ziel ist, den Widerstand gegen die Aktivitäten der Linkskriminellen zu fördern“, ${ }^{58}$ heißt es dazu auf der Seite „Sicherheitshinweise für Nationalisten". Das soll im Endeffekt dazu dienen, Gegner ausfindig zu machen und einzuschüchtern. Häufig werden die Daten sowie Bilder dieser Personen im Internet veröffentlicht, ein Beispiel ist die Webpräsenz der "Freien Kräfte - Schwarzwald-BaarHeuberg", die nicht davor zurückschrecken, Daten von minderjährigen Jugendlichen zu veröffentlichen. ${ }^{159}$ Die AN sind eine eigene rechtsextreme Subkultur, die Jugendlichen eine modern anmutende und aktionsorientierte Erlebniswelt mit ästhetischem Charakter anbieten. Diese Erlebniswelt erstreckt sich nicht nur auf die Straße, sondern auch auf die virtuelle Welt, wie im nächsten Kapitel verdeutlicht wird.

151 Freie Nationalisten Siegerland, Nationale „Recht-auf-Zukunft“ - Demonstration in Recklinghausen, 1.12.2009, [htt ps://fnsi.wordpress.com/2009/12/01/nationale-\%E2\%80\%9Erecht-auf-zukunft-demonstration\%E2\%80\%9C-inrecklinghausen/], eingesehen 21.1.2015.

152 Baron, Selbstverständnis, S. 448.

153 Suermann, Rebel, S. 179.

154 Baron, Selbstverständnis, S. 446

155 Blog: AN Ostfriesland, Über uns.

156 Suermann, Rebel, S. 444.

157 Blog: Autonome Nationalisten Ostfriesland, Nützliches, o.D., [http://logr.org/leerostfriesland/nutzliches/], eingesehen 16.2.2015.

158 Sicherheitshinweise für Nationalisten, Recherche gegen Linkskriminelle, o. D., [http://www.s-f-n.org/allgemeinehinweise/anti-antifa-recherchen/2.html], eingesehen 21.1.2015.

159 Freie Kräfte - Schwarzwald-Baar-Heuberg, Kampf gegen Phantom-Gewalttäter in Villingen-Schwenningen, 22.1.2012, [http://fk-sbh.net/2012/01/kampf-gegen-phantom-gewalttater-in-villingen-schwenningen/], eingesehen 21.1.2015. 


\section{Propaganda im Internet}

"Das World Wide Web ist ein Schaufenster des deutschen und internationalen Rechtsextremismus", 160 schrieb Thomas Pfeiffer 2009. Neben den Aktionen auf der StraBe und bei Demonstrationen ist das Internet das wohl wichtigste Propagandainstrument. Das beschränkt sich nicht nur auf AN, sondern auf die gesamte rechtsextreme Szene. Diese erkannte früh die Möglichkeiten des Internets: Bereits Mitte der 1990er, als das Internet noch kein Massenphänomen war, verbreitete sie darin ihre Botschaften in Form des Thule-Netzes. ${ }^{161}$ Damals wie heute hat das Internet eine hohe Attraktivität, um Botschaften zu verbreiten und diese gleichzeitig einer immer größer werdenden virtuellen Öffentlichkeit zugänglich zu machen. Heute besteht ein beinahe grenzenloses Angebot an Webseiten mit rechtsextremen Inhalten. Allerdings herrscht bei diesen Seiten eine beträchtliche Fluktuation, d.h. sie sind aus unterschiedlichsten Gründen etwa aus taktischen oder strafrechtlichen - oft nur sehr kurzzeitig verfügbar. Dennoch haben sie sich in den wichtigsten Plattformen wie Youtube, Facebook oder Twitter dauerhaft festgesetzt und somit kommt eine breite Öffentlichkeit mit den entsprechenden Inhalten in Berührung.

Daneben besteht eine regelrechte Parallelwelt samt eigenen sozialen Netzwerken, Blogportalen sowie Nachrichtenseiten. Mit Metapedia existiert sogar eine rechtsextreme Online-Enzyklopädie nach dem Vorbild von Wikipedia. Diese ist voll mit rassistischen, geschichtsrevisionistischen sowie sonstigen menschenverachtenden und verhetzenden Inhalten. ${ }^{162}$ Es wird versucht, eine Gegenhegemonie im virtuellen Raum zu erreichen, mit dem Ziel, vom rechten Rand aus in die Mitte der Gesellschaft zu agitieren. In diese Parallelwelt sind die AN fest eingebunden, so dient ihnen „logr.org" als die Blogplattform, gemacht von und für Neonazis - zahlreichen AN-Gruppierungen dient sie als Webpräsenz. Es ist kein Zufall, dass die Seite auf einem US-amerikanischen Server betrieben wird, ${ }^{163}$ um so dem deutschen Strafrecht zu entgehen. "Meinungsfreiheit ist Menschenrecht"164 lautet es auf der Startseite, dadurch wird bereits der selbstinszenierte Opferstatus angedeutet. Allerdings nimmt der Anteil an strafrechtlich relevanten Inhalten ab, sie bewegen sich mehr und mehr am Rande des Erlaubten. ${ }^{165}$ Meist ist aus den Erklärungen die Ablehnung von sozialdarwinistischen Positionen zu entnehmen, dafür rücken Ethnopluralismus bzw. Ethnozentrismus verbunden mit völkisch-nationalistischen, antikapitalistischen und globalisierungskritischen Positionen ins Zentrum. ${ }^{166}$

160 Thomas Pfeiffer, Virtuelle Gegenöffentlichkeit und Ausweg aus dem „rechten Ghetto“. Strategische Funktionen des Internets für den deutschen Rechtsextremismus, in: Braun/Geilser/Gerster (Hrsg.), Strategien, S. 290-307, hier S. 290.

161 Thomas A. Wetzstein/Hermann Dahm/Linda Steinmetz, Datenreisende. Die Kultur der Computernetze, Opladen 1995, S. 147-170.

162 Metapedia, Willkommen bei Metapedia, o. D., [http://de.metapedia.org/wiki/Hauptseite], eingesehen 23.2.2015.

163 Logr Bloghosting, Impressum, o. D., [http://logr.org/impressum/], eingesehen 23.2.2015.

164 Logr Bloghosting, Startseite, o. D., [http://logr.org/], eingesehen 23.2.2015.

165 Pfeiffer, Gegenöffentlichkeit, S. 306.

166 Autonome Nationalisten Göppingen, Autonom?, o. D., [http://angp.demo-goeppingen.org/autonom/], eingesehen 24.2.2015. 
„In ganz Europa gibt es die selben Probleme! Überfremdung, Kapitalismus, Arbeitslosigkeit....die Völker Europas sterben. [...] Die freien Völker Europas, ja selbst die freien Völker im nahen [sic!] Osten und Asien haben alle den selben Feind." 167

Darüber hinaus bestehen zahlreiche Webshops für Flugblätter, Plakate, Kleidung, Musik und dergleichen, z.B. die Versandfirma "Antisem Versand" mit der bezeichnenden Adresse „antisem.it". ${ }^{168}$ In zynischer Weise wird hier "Für Demokratie und Toleranz :D“169 geworben. Es verwundert nicht, dass der Versand in Dortmund ansässig ist, einer der Hochburgen für Autonome Nationalisten. ${ }^{170}$ Außerdem ist der Betreiber Michael Brück Mitglied in der Partei „Die Rechte“, einem Sammelbecken der AN. ${ }^{171}$

Ähnlich wie im realen Leben wird im Internet auf mittlerweile professionell gestalteten Seiten eine ästhetische und interaktive Erlebniswelt angeboten, die mit audiovisuellen Inhalten angefüttert ist - der Rechtsextremismus ist längst im Web 2.0. angekommen. Auf die Verwendung von Frakturschrift wird anders als noch bei den Kameradschaften bewusst verzichtet, stattdessen wird eine moderne, oft dem Graffitistil entlehnte Schrift verwendet. In aufwändig gestalteten Videos, meist mit dramatisch-orchestraler oder rockiger Musik untermauert, werden Aktionen dokumentiert bzw. es wird zu Aktionismus aufgerufen. Im Video „Werde unsterblich“ ziehen weiß maskierte Aktivisten mit Fackeln nachts durch Bautzen. ${ }^{172}$ Die Ähnlichkeit mit der Anonymous-Bewegung liegt auf der Hand. Durch geschickte Kameraführung, Schnitt und Bearbeitung wird der Eindruck erweckt, es handle sich um eine riesige Masse von Demonstranten, die Untermalung mit theatralischer Musik verstärkt den Eindruck zusätzlich. Mit dem Slogan „Damit die Nachwelt nicht vergisst, dass du Deutscher gewesen bist!"173 wird zum Aktivismus aufgerufen. Mit fast 160.000 Aufrufen kann angenommen werden, dass dieses Video eine gewisse Breitenwirkung nicht verfehlt hat.

Durch die jugendaffine Gestaltung der Webseiten wird eine progressive, neue und dynamische Jugendbewegung dargestellt, wobei die Umsetzung von gezielten und öffentlichkeitswirksamen Aktionen sowie der Erlebnischarakter klar im Vordergrund stehen. Die Vermittlung und Verfestigung von Ideologie schwingt im Hintergrund mit - ähnliches war bereits bei den Skinheads der Fall. In Gramscis Sinne setzen sie auf „ein[en] Geist der Abspaltung, der bestrebt sein muss, sich von der protagonistischen Klasse auf die potentiell verbündeten Klassen auszuweiten"174. Die potentiell verbündeten Klassen stellen in diesem Fall die gesamte Öffentlichkeit, aber vor allem die Ju-

167 Autonome Nationalisten Ostfriesland, Auf auf ins neue Kampfiahr 2010!, 2.1.2010, [https://logr.org/leerostfriesland/2010/01/02/auf-auf-ins-neue-kampfahr-2010/], eingesehen 28.3.2016.

168 Antisem Versand, Startseite, o. D., [http://www.antisem.it/], eingesehen 24.2.2015.

169 Ebd.

170 Sager, Freund, S. 111.

171 Die Rechte, Landesverband NRW gegründet, 16.9.2012, [http://die-rechte.com/landesverband-nrw-gegruendet/], eingesehen 15.2.2015.

172 Youtube LLC, PatrioticTrailerAct, Werde Unsterblich - Demonstration in Bautzen, 2.5.2011, [https://www.youtube. $\mathrm{com} /$ watch?v=bkU6KTjLTYU], eingesehen 24.2.2015. 
gend dar. Die elektronischen Sturmtruppen sind auf dem Vormarsch und als ständige Begleiterin und sozusagen als Soundtrack dazu dient die rechtsextreme Musik.

\section{Die Rolle der Musik}

\section{Rechtsrock}

War die Berichterstattung außerhalb der Skinheadszene das wichtigste Medium für das Bild, das in der Öffentlichkeit herrscht, so war die Musik das bedeutendste Medium innerhalb der Subkultur. Rechtsrock bezeichnet kein eigenes Musikgenre, sondern "lediglich eine Klassifizierung für den politischen Inhalt der Lieder".175 Auch die Bandbesetzungen, meist Schlagzeug, Bass, Gitarre und Gesang, sowie die Spielart unterscheiden sich keineswegs von nichtrechten Genrevertretern. Dennoch bezeichnen Christian Dornbusch und Jan Raabe rechtsextreme Musik, die aus dem Oi!- bzw Streetpunk hervorgegangen ist, als klassischen Rechtsrock. ${ }^{176}$ Skrewdriver veröffentlichten ab 1985 ihre Alben beim rechtslastigen deutschen Plattenlabel Rock-o-Rama. ${ }^{177}$ Wie vorher schon angedeutet, sollten die Böhsen Onkelz, die wohl umstrittenste Band Deutschlands, bald einen mindestens gleichwertigen Status als Kultband einnehmen. Doch schon vorher hatte „die Oi!-Szene [...] das Brandmal einer Marschmusik für Nazis und Rassisten verpasst bekommen".178

Die Böhsen Onkelz standen seit 1984 bei Rock-o-Rama unter Vertrag. ${ }^{179}$ Die vier Musiker aus Frankfurt begannen Ende der 1970er als pubertierende Punks und entwickelten sich zunächst zur bedeutendsten Skinheadband im deutschsprachigen Raum. ${ }^{180}$ Ähnlich wie Skrewdriver hatten sie eine Vorbild- und Idolfunktion. Sie galten als erste wirkliche deutsche Rechtsrockband. Die Lieder wurden von nun an auf Deutsch gesungen, die ausschließliche Orientierung an England rückte in den Hintergrund. Zwei Lieder auf Demotapes, die jedoch nie auf einem Album veröffentlicht wurden, brachten der Band bis heute ein rechtsextremes Image ein. Das Lied „Türken raus“"181 entstand noch in ihrer Punkphase. Sowohl Farin und Seidel-Pielen als auch Richter sehen hier noch keinen politischen Hintergrund, sondern diffusen pubertären Hass. ${ }^{182}$ Trotzdem gilt es als richtungsweisend für den deutschen Rechtsrock, da erstmals offen Ausländerhass in einem Lied propagiert wurde. In "Deutschland den Deutschen", 183 das bereits

\footnotetext{
175 Christian Dornbusch/Jan Raabe, RechtsRock, in: Forschungsjournal NSB 19 (2006), Heft 2, S. 47-52, hier S. 47.

176 Ebd.

177 Aschwanden, Rechtsextremismus, S. 157.

178 Farin/Seidel-Pielen, Skinheads, S.99.

179 Stefan Richter, "Gehasst - Verdammt - Vergöttert". Das Phänomen der ehemaligen Skinhead-Kultband "Böhse Onkelz" und ihre Bezüge zum Rechtsextremismus, in: Herbert Kloninger (Hrsg.), Rechtsextremismus als Gesellschaftsphänomen. Jugendhintergrund und Psychologie, Brühl 2006, S. 110-189, hier S. 113, [http://edoc.vifapol. de/opus/volltexte/2009/1249/pdf/band_27.pdf], eingesehen 15.1.2015.

180 Bredel, Skinheads, S. 258.

181 Youtube LLC, miralis dhiskoloss, Böhse Onkelz - Türken Raus, 19.4.2008, [https://www.youtube.com/ watch?v=vJRtyu6xIw8], eingesehen 15.1.2015.

182 Farin/Seidel-Pielen, Skinheads, S. 80 f.; Richter, Gehasst, S. 118-120.

183 Youtube LLC, Kanal von XxxjohndeerexxX, Böhse Onkelz - Deutschland den Deutschen HQ (demo-album), 2.2.2012, [https://www.youtube.com/watch? $v=$ gYpfUInTNR8], eingesehen 15.1.2015.
} 
in der Skinheadphase entstand, mussten Ausländer für das Fehlen von Perspektiven herhalten:

„Deutschland versinkt in Schutt und Dreck, und ihr, ihr Schweine, ihr seht einfach weg. [...] Lange genug habt ihr mit angesehn, wie unsere Städte zugrunde gehen! [...] Skinhead ist Zusammenhalt gegen euch und eure Kanakenwelt! Deutschland den Deutschen!"184

Damit drückten sie aus, was sich viele Skins damals dachten, sie waren sozusagen das Sprachrohr der Szene. Das 1984 erfolgreich erschienene Debutalbum „Der nette Mann”, das bei Rock-o-Rama erschien, erlangte bald Kultstatus bei rechtsextrem orientierten Skinheads. Ein Grund ist sicherlich die Indizierung der Bundesprüfstelle für jugendgefährdende Schriften (BPjS) im Jahr 1986,185 das Verbotene hat bekanntlich immer seinen besonderen Reiz. Auf dem Album waren keine eindeutig neonazistisch motivierten Stücke zu hören, dennoch schwingt bei „Deutschland“186 eine gehörige Portion Nationalismus mit: „Den Stolz, deutsch zu sein, wollen sie dir nehmen, das Land in den Dreck ziehen, deine Fahne verhöhnen. Doch wir sind stolz, in dir geboren zu sein, wir sind stolz drauf, Deutsche zu sein." 187 Aber ebenso distanzierten sie sich in diesem Lied von der Zeit der Nazi-Diktatur: „Auch zwölf dunkle Jahre in deiner Geschichte machen unsere Verbundenheit zu dir nicht zunichte. [...] Schwarz-Rot-Gold, wir stehn'zu dir!"188 Trotzdem stellte dieser offene Nationalismus einen Tabubruch in der deutschen Musikszene dar, ${ }^{189}$ interessanterweise wurde dieses Lied aber von der BPjS nicht indiziert. ${ }^{190}$ Sehr ambivalent ist auch der Refrain zu "Frankreich '84" zu bewerten: „Ja, wir sehn uns in jedem Fall, im Sommer '84 beim Frankreichüberfall“. ${ }^{191}$ War dies eine Anspielung auf Hitlers Überfall auf Frankreich, war es bewusste Provokation oder hatte dies nur mit der Hooliganszene bezüglich der Fußballeuropameisterschaft 1984 zu tun? Die BPjS hatte dieses Stück als neonazistisch eingestuft und indiziert. Stefan Richter sieht es hingegen als überbewertet, da der Hintergrund zur Hooliganszene zu wenig berücksichtigt wurde, ${ }^{192}$ Farin und Seidel-Pielen bezeichnen das Urteil als "surrealistisch“.193 Jedenfalls untermauerten Lieder dieser Art sowie die Indizierung des Albums das rechtsextreme Image der Band. Nach „Der nette Mann“ orientierte sich Rock-o-Rama fast ausschließlich nach rechts und wurde in weiterer Folge zum bedeutendsten und größten Plattenlabel für rechte Musik. ${ }^{194}$ Und die Böhsen Onkelz müssen sich auch einen weiteren Vorwurf gefallen lassen: Im Jahr 1985 spielten sie ein großes Konzert zusammen mit

\footnotetext{
184 Youtube, Böhse Onkelz - Deutschland den Deutschen.

185 Bredel, Skinheads, S. 259 f.

186 Youtube LLC, 19Thunder90, Böhse Onkelz - Deutschland, 4.8.2012, [https://www.youtube.com/watch?v=tCq Gcelhvjw], eingesehen 15.1.2015.

187 Ebd.

188 Ebd.

189 Richter, Gehasst, S. 130.

190 Bredel, Skinheads, S. 262

191 Youtube LLC, Lukas Martin Hopfner, Böhse Onkelz - Frankreich '84, 25.2.2008, [https://www.youtube.com/ watch?v=PfKyn111 u8o], eingesehen 16.1.2015.

192 Richter, Gehasst, S. 125-127

193 Farin/Seidel-Pielen, Skinheads, S. 87.

194 Richter, Gehasst, S. 113.
} 
der ultrarechten Band Kraft durch Froide in deren Proberaum, dem KdF-Bunker. ${ }^{195}$ Dabei schienen Sieg-Heil-, Deutschland-den-Deutschen- und Ausländer-Raus-Rufe die Band ebenso wenig zu stören wie die Hitlergrüße aus dem Publikum. ${ }^{196}$

Als die rechtsextemen Auswüchse zunahmen und neonazistische Gruppierungen immer mehr Einfluss gewannen, stiegen sie 1986 aus der Szene aus, kurz nachdem zwei Türken in Hamburg von Skinheads umgebracht wurden. ${ }^{197}$ In weiterer Folge beendeten sie die Zusammenarbeit mit Rock-o-Rama. Die Haare wuchsen auf Schulterlänge und auch musikalisch orientierten sie sich von nun an in Richtung Heavy Metal. In Interviews und Liedern distanzierten sie sich mehrfach vom Rechtsextremismus, dennoch wurden sie von Seiten der Medien entweder nicht beachtet oder die Glaubwürdigkeit der Band wurde in Frage gestellt. ${ }^{198}$ Folglich boykottierten sie seitdem bis auf wenige Ausnahmen jegliche Medien, was sich in zahlreichen Liedtexten widerspiegelt, z.B. „Was glaubt ihr zu wissen, was glaubt ihr, wer wir sind? Ihr habt jahrelang gelogen, die Presse stinkt!".199 Im Grunde schlachteten die Medien ihren schlechten Ruf aus und lieferten ihnen andererseits vielfach Inspiration für neues Liedmaterial - eine erfolgreiche Symbiose, die von einer tiefen beiderseitigen Ablehnung gekennzeichnet ist. Derartige pressekritische Texte lassen die Band - ob gewollt oder nicht - jedoch wieder auf die rechte Seite rücken: Der Vorwurf der Lügenpresse ist nicht neu und charakteristisch für rechtsextreme Gruppierungen. Gerade die jüngste Vergangenheit zeigt das anhand der Pegida-Demonstrationen.

In rechtsextremen Kreisen sind die Böhsen Onkelz zu großen Teilen verhasst. Andererseits wird der Mythos dennoch am Leben gehalten, um die große Bekanntheit der Band als Zugpferd für rechtsextreme Zwecke zu missbrauchen. ${ }^{200}$ Die Selbstinszenierung als ewige Außenseiter und Unterdrückte deckt sich mit vielen Ansichten des rechtsextremen Spektrums. Mit Textpassagen wie "Mit scheinheiligen Liedern erobern wir die Welt"201 spielen sie bewusst mit ihrer Vergangenheit und halten dabei ihren polarisierenden Status hoch. Im Endeffekt sind sie Medienprofis ohne Medien, die eben durch die Instrumentalisierung ihrer umstrittenen Vergangenheit zu einer der erfolgreichsten deutschen Bands aufgestiegen sind. Nach Jahren massiver Kritik mehrten sich die Stimmen, die Band nicht mehr zu isolieren und gegen Rechts einzusetzen. So auch Patrick Orth, der aus dem Umfeld der Toten Hosen stammt, die zu den größten Kritikern der Böhsen Onkelz zählen:

„Heute haben sie für mich eine wichtige Sozialarbeiter-Funktion, indem sie Teenager-Dumm-Prolls, die politisch auf der Kippe stehen, sagen können:,Wir

195 Youtube LLC, Kanal von Kautzmusik, Böhse Onkelz - Bunkerskins - Live in Berlin 1985 Komplett, 10.7.2013, [https://www.youtube.com/watch?v=nGuKNI1Hy_A], eingesehen 16.1.2015.

196 Ebd., 5:47-6:31.

197 Bredel, Skinheads, S. 263.

198 Richter, Gehasst, S. 115.

199 Youtube LLC, Frei.Onkel, Böhse Onkelz - Fahrt zur Hölle |+Text, 1.7.2014, [https://www.youtube.com/watch?v $=\mathrm{XY} 9 \mathrm{VhYDKmPg]}$, eingesehen 12.2.2015.

200 Richter, Gehasst, S. 150-156.

201 Youtube LLC, Midgard, BÖHSE ONKELZ - Heilige Lieder, 23.2.2009, [https://www.youtube.com/watch?v=Qv4f kiLnIDk], eingesehen 12.2.2015. 
waren früher wie Ihr [sic!]. Aber wir können Euch [sic!] heute sagen, dass dieser ganze Nazi-Kram totaler Schwachsinn ist. Wir haben den Fehler gemacht. Macht Ihr [sic!] ihn nicht auch!"'202

Das kann funktionieren, aber ebenso gefährlich sein, da schnell eine Brücke zur Vergangenheit geschlagen werden kann.

Der Ausstieg der Band aus der rechtsextremen Skinheadszene hinterließ eine große Lücke, aber schon bald schossen Bands aus dem Boden, die die Böhsen Onkelz als Chorknaben dastehen ließen. Häufig sind diese Bands schon am Namen erkennbar, wie die bereits erwähnten Kraft durch Froide oder Radikahl, Hassgesang, Oithanasie, Kommando Freisler und Stahlgewitter. Viele dieser Gruppen sehen sich selbst als Skinheads. Vor allem seit $1990^{203}$ wird vielfach ganz offen der historische Nationalsozialismus angepriesen, der Holocaust geleugnet sowie gegen Ausländer und Linke gehetzt. „Mächtig sind seine Schwingen, die Krallen scharf wie Klingen, wie unser Stolz bleibt er auf ewig unbesiegt, auf dass des Reiches Adler endlich wieder fliegt" ${ }^{\prime 204}$ von Stahlgewitter ist nur eines der zahlreichen Beispiele. Landser, eine der extremsten Bands, scheuen nicht davor zurück, zu Gewalt und Mord aufzurufen: „Irgendwer wollte den Niggern erzählen, sie hätten hier das freie Recht zu wählen. Recht zu wählen das haben sie auch, Strick um den Hals oder Kugel in den Bauch." ${ }^{205}$ Nicht umsonst wurde die Band 2003 als kriminelle Organisation eingestuft und verboten. ${ }^{206}$

Nach der deutschen Wiedervereinigung boomte das Geschäft mit rechtsextremer Musik, speziell in den neuen Bundesländern.207 Das erkannte auch die NPD: Um die Jahrtausendwende begann sie verstärkt, Rechtsrockbands auf den Parteiveranstaltungen Auftrittsmöglichkeiten zu geben.208 Die Verflechtung zwischen Partei und Musikern wurde immer enger, so ist z.B. Michael Regener, der Bandleader von Landser, selbst NPD-Mitglied. ${ }^{209}$ Durch diese Liaisonen entstanden ab 2004 die sogenannten Schulhof-CDs, zunächst aus dem Umkreis der Freien Kameradschaften, die NPD legte noch im selben Jahr nach. ${ }^{210}$ Diese speziell auf Heranwachsende zugeschnittenen Materialien wurden nicht nur auf Schulhöfen und Jugendtreffs verteilt, sondern auch im Internet kostenlos zum Download angeboten. ${ }^{211}$ Damit wird von rechtsextremer Seite

202 Die Toten Hosen, Patrick Orth, März 2005, [http://www.dietotenhosen.de/band/freunde-des-hauses/patrickorth], eingesehen 12.1.2015.

203 Bredel, Skinheads, S. $270 \mathrm{f}$.

204 Youtube LLC, WiderstandMusik, Stahlgewitter - Auf das der Adler wieder fliegt [HQ], 18.9.2014, [https://www. youtube.com/watch?v=ipcSAZDR31M], eingesehen 12.2.2015.

205 Ebd., DK Snopy, Landser - Niemals, 29.11.2014, [https://www.youtube.com/watch?v=puDO8nypFfM], eingesehen 12.2.2015.

206 Bundesgerichtshof, Beschluss vom 22. April 2003, 22.4.2003, [http://juris.bundesgerichtshof.de/cgi-bin/recht sprechung/document.py?Gericht=bgh\&Art=en\&nr=26144\&pos=0\&anz=1], eingesehen 5.2.2015.

207 Aschwanden, Rechtsextremismus, S. 144 f.

208 Langebach/Raabe, Freizeit, S. $166 \mathrm{f}$.

209 Ebd., S. 172.

210 Thomas Pfeiffer, Erlebniswelt Rechtsextremismus. Menschenverachtung mit Unterhaltungswert, in: Caroline Y. Robertson-von Trotha (Hrsg.), Rechtsextremismus in Deutschland und Europa. Rechts außen - Rechts ,Mitte'? (Kulturwissenschaft interdisziplinär 7), Baden-Baden 2011, S. 117-131, hier S. $121 \mathrm{f}$.

211 Hans Peter Killguss/Jan Schedler, Jugendarbeit der extremen Rechten und das Beispiel PRO KÖLN und PRO NRW, in: Alexander Häusler (Hrsg.), Rechtspopulismus als „Bürgerbewegung“. Kampagnen gegen Islam und Moscheebau und kommunale Gegenstrategien, Wiesbaden 2008, S. 129-151, hier S. 132 f. 
versucht, speziell junge, ungefestigte Menschen für sich zu gewinnen. Dafür eignet sich gerade Musik hervorragend als Eintrittstor in die Szene.

Nicht nur harte, rockige Titel sind auf den Samplern vorhanden, sondern auch emotionsgeladene Balladen. Musik hat als Propagandawaffe den Vorteil, dass die vermittelten Botschaften umso mehr wirken, je öfter sie gehört werden. Herkömmliche Parteiwerbung landet dagegen schnell mal im Papierkorb. Dabei wurde seit dem Verbot des deutschen Ablegers von B\&H im Jahr $2000^{212}$ vermehrt darauf geachtet, nur mehr bis an die Grenze zur Legalität zu gehen. ${ }^{213}$ Der Reiz des Verbotenen, des Tabubehafteten schwingt hier aber trotzdem mit. Zusätzlich hat sich die Qualität der Musik stark erhöht, dumpf und stümperhaft produzierte Aufnahmen gehören eher der Vergangenheit an. Besonders erfolgreich waren diese Veröffentlichungen wie schon nach der Wiedervereinigung im Osten Deutschlands. ${ }^{214}$

Abseits der Tonträger bieten die konspirativen Rechtsrockkonzerte eine für Jugendliche spannende Abenteuerwelt, angefangen vom Katz-und-Maus-Spiel mit der Polizei zum geheimen Veranstaltungsort bis zum gemeinsamen Gruppenerlebnis mit gröhlenden Gleichgesinnten samt Hitlergruß. Armin Pfahl-Traughber spricht der Musik eine Mobilisierungs-, Integrations- und Politisierungsfunktion zu. ${ }^{215}$ Rechtsrock ist eines der wichtigsten Medien der rechtsextremen Agitation, ihren Ausgangspunkt hatte sie in der rechtsextremen Skinheadbewegung, in der die Musik zentral ist. Die Bandbreite der musikalischen Stilrichtungen rechtsextremer Musik wurde genau wie die rechtsextreme Jugendkultur im Allgemeinen heterogener, laut Martin Langebach und Jan Raabe ist daher berechtigterweise von „Plural anstatt Singular"216 zu sprechen.

\section{Jenseits des klassischen Rechtsrocks}

Wie schon angedeutet bewegt sich rechtsextreme Musik nicht nur innerhalb des klassischen Rechtsrocks, sondern es wird zunehmend versucht, andere Musikstile zu ,entern'. Seit Anfang der 1990er etablierte sich die rechtsextreme Liedermacherszene, der Impuls dazu kam wieder aus England und zwar von lan Stuarts countrylastigen Nebenprojekten. ${ }^{217}$ Die bekanntesten deutschen Protagonisten sind das NPD-Mitglied Frank Rennicke und Anett Müller. Letztere verzeichnete mit dem Lied „Wir hassen Kinderschänder"218 einen Hit auf Youtube, was die Zahl von 1.363.919 Aufrufen bestätigt. Wieder kann angenommen werden, dass nicht nur Zugriffe aus dem rechtsext-

212 Jan Raabe/Martin Langebach, Jugendkulturelle Dynamik - Vom Hardcore über den NSHC zu den, Autonomen Nationalisten', in: Schedler/Häusler, Autonome Nationalisten, S. 154-166, hier S. 164.

213 Senatsverwaltung für Inneres und Sport Berlin, Rechtsextremistische Musik, o. D. (Dezember 2012), S. 10, [http:// www.berlin.de/imperia/md/content/seninn/verfassungsschutz/musik_brosch__re_online.pdf?start\&ts=135583 7361\&file=musik_brosch_re_online.pdf], eingesehen 13.2.2015.

214 Killguss/Schedler, Jugendarbeit, S. $133 \mathrm{f}$.

215 Armin Pfahl-Traughber, Politisches Selbstverständnis und Gewaltorientierung rechtsextremistischer Skinheads Eine Fallstudie zu den Tonträgern der Band "Landser", in: Jahrbuch Extremismus \& Demokratie 13 (2001), S. 169-182, hier S. 170.

216 Langebach/Raabe, Freizeit, S. 167

217 Ebd., S. 176.

218 Youtube LLC, skhldfl, Annett - WIR HASSEN KINDERSCHÄNDER, 16.2.2008, [https://www.youtube.com/watch?v= Idu3kB8_r90], eingesehen 26.2.2015. 
remen Spektrum erfolgt sind. Zwar enthält dieses Lied keine explizit rechtsextremen Inhalte, jedoch besingt die Liedermacherin in anderen Stücken eindeutig völkischnationalistisch motivierte Inhalte, so z.B.. „Vermischung pur, ist das das Ende vom Lied? Und es eine Minderheit an Deutschen in Deutschland gibt."219 Gegen Rennicke ist Müller verhältnismäßig zurückhaltend, denn seine Texte sind voll von geschichtsrevisionistischen Inhalten. Unter anderem glorifiziert er in seinen Liedern Rudolf Hess ${ }^{220}$ und Adolf Hitler 221 , außerdem fordert er in "Schlesien uns von Gott gegeben“222 die alten Grenzen des Dritten Reichs ein. Rennickes Werke sind durchzogen von der Meinung, dass die „Legitimität politischer Herrschaft [...] nur auf der Grundlage ethnisch homogener Volksgemeinschaften zu erreichen [sei]".223 Anders als der Rechtsrock klingen Liedermacherlnnen mit ihren oft balladenhaften Songs beim ersten Hinhören relativ harmlos. Insbesondere Frank Rennicke verwendet oft schon bekannte und eingängige Melodien in seiner Musik. ${ }^{224}$ Aber gerade das macht sie gefährlich, zudem dürfte diese Art von Musik auch ältere Menschen ansprechen.

Im Gegensatz dazu steht der nationalsozialistische Black Metal (NSBM). Black Metal ist eine der extremsten Spielarten innerhalb des Metals. Charakterisieren lässt sich die Musik im Allgemeinen durch eine extrem schnelle Spielweise, die mit einer meist unverständlichen kreischenden oder tief gröhlenden Stimme untermalt ist. In diesem Genre sind misanthropisches, elitäres sowie sozialdarwinistisches Denken weit verbreitet. 225 Es existiert kein fest definierbarer bzw. abgrenzbarer rechter Flügel, eher sind die Übergänge fließend und die Subkultur als Ganzes zu betrachten. ${ }^{226}$ Der Großteil von der Szene lehnt die Vermischung von politischen Zielen und der Musik ab, die Akzeptanz von rechtsextremen Umtrieben ist jedoch bei einer erheblichen Anzahl von Bands ziemlich hoch. ${ }^{227}$ Die Texte beziehen sich oft auf „Satanismus, Okkultismus, Krieg gegen das Christentum und verstärkt nordisch-germanische[n] ,Artglaube[n] "'228 - ideale Anknüpfungspunkte für rechtsextreme Ideologien. Vor allem der Black Metal skandinavischer Prägung Anfang der 1990er-Jahre war von rechtsextremen Einstellungen geprägt ${ }^{229}$ und bereits Mitte der 1990er breiteten sich am rechten Rand der deutschen Black Metal-Szene neonazistische Tendenzen ${ }^{230}$ aus. Die wichtigsten Vertreter der deutschen NSBM-Szene sind laut Dornbusch und Killguss die Gebrüder Hendrik und Ro-

219 Youtube LLC, Kanal von ANBueckeburg, Annett - Zeit, zu rebellieren, 1.11.2011, [https://www.youtube.com/ watch?v=RywJbVwlobY], eingesehen 26.2.2015.

220 Ebd., pamadere, Frank Rennicke - Rudolf Hess, 14.12.2011, [https://www.youtube.com/watch?v=N-XdeSZghok], eingesehen 26.2.2015.

221 Ebd., Michael Wagner, Frank Rennicke - Birthday im April, 19.4.2014, [https://www.youtube.com/watch?v=_cQS sq-LVro], eingesehen 26.2.2015.

222 Ebd., Das Reich, Frank Rennicke Schlesien uns von Gott Gegeben Deutsche Musik, 7.6.2014, [https://www.youtu be.com/watch? $v=21 x G N Q b s X I Y]$, eingesehen 26.2.2015.

223 Claus Leggewie, Der Kampf um die europäische Erinnerung. Ein Schlachtfeld wird besichtigt, München 2011, S. 27.

224 Langebach/Raabe, Freizeit, S. 177.

225 Christian Dornbusch/Hans-Peter Killguss, Unheilige Allianzen. Black Metal zwischen Satanismus, Heidentum und Neonazismus, Münster 2005, S. 9.

226 Ebd., S. 147

227 Ebd.

228 Langebach/Raabe, Freizeit, S. 181

229 Dornbusch/Killguss, Allianzen, S. 36-41.

230 Ebd., S. 58. 
nald Möbus von der Band Absurd. ${ }^{231}$ Stellvertretend für viele NSBM-Bands verbinden sie neogermanisches Heidentum mit nationalsozialistischer Ideologie.

"In den Divisionen Wiking und Nordland waren geeint, unsre Ahnen unerschütterlich für das Reich gegen den Feind. Ihre Ehre die hieß Treue, in den Adern floss ein Blut [...] Ein einig Volk, ein Glaube an uralte Heidenmacht." ${ }^{\prime 232}$

Es dauerte nicht lange, bis NSBM- und Rechtsrockinterpreten als Brüder im Geiste zusammenfanden. Darüber hinaus haben viele neonazistische Skinheads eine Vorliebe für die germanische Mythologie. ${ }^{233}$ Durch diese Berührungspunkte kam es seit etwa der Jahrtausendwende zu gemeinsamen Auftritten von nationalsozialistischen Black Metallern und rechtsextremen Skinheadbands. ${ }^{234}$

Ein etwas neueres Phänomen, zumindest in Deutschland, ist der Nationalsocialist Hardcore (NSHC) oder auch Hatecore. Dem zugrunde liegt der Hardcore, der Anfang der 1980er-Jahre in den USA aus dem Punk heraus entstand. ${ }^{235}$ Ähnlich wie die Oi!-Bewegung entstand eine Subkultur, die die noch junge Punkbewegung bereits wieder am Ende sah.236 Der Musikstil des Hardcore ist härter, schneller und aggressiver als Punk, oftmals auch druckvoller durch die tiefer gestimmten Gitarren. Das Do-it-Yourself-Prinzip wurde übernommen und bei einem großen Teil der Hardcoreszene besteht eine "relative Nähe zu radikal linken Positionen".237

Doch auch bei Skinheads und Neonazis fand diese energiereiche und dynamische Musik Anklang und so entstanden in den USA Ende der 1980er mit den Blue Eyed Devils, Angry Aryans oder Bound For Glory die ersten NSHC-Bands, die den Hardcoresound sowie deren Habitus adaptierten. 238 Dieser Stil wurde etwa Ende der 1990er nach Europa exportiert und langsam entstanden auch deutsche Bands, die sich dem NSHC zuwandten. ${ }^{239}$ Musikalisch lassen sich die Bands - auch hinsichtlich einer qualitativ hochwertigen Produktion - außer anhand des Textes kaum mehr von anderen Hardcorebands unterscheiden, d.h. auch außerhalb der NSHC-Szene kann die Musik Anklang finden. Die meisten deutschen Bands verfassen ihre Texte auf Englisch, was mitunter auch Kritik aus der Rechtsrockszene hervorruft, 240 jedoch ist die Musik dann noch schwerer vom üblichen Hardcore zu trennen. Neben der Musik wurden auch Symbole, Kleidung und sogar Lebenseinstellungen des Hardcore kopiert. Innerhalb der Hardcoreszene entstanden Strömungen, die - in unterschiedlichem Ausmaß - den Straight-EdgeGedanken in den Mittelpunkt stellten, d.h. bewusster Verzicht auf Drogen jeglicher Art,

231 Dornbusch/Killguss, Allianzen, S. 168.

232 Youtube LLC, poopietreat666, Absurd - Asgardsrei - Germanien über alles (Remixed, Revised \& Remastered), 12.7.2012, [https://www.youtube.com/watch?v=olfbpArtn8s], eingesehen 26.2.2015.

233 Dornbusch/Killguss, Allianzen, S. 275.

234 Ebd., S. $286 \mathrm{f}$.

235 Christian Schulze/Regina Wamper, „Adolf H. didn't booze or smoke“. Konsumkritik, Jugendkultur, Drogenverzicht von Rechts: Die neonazistische Adaption von Hardcore und Straight Edge, in: Wamper/Kellersohn/Dietzsch (Hrsg.), Rechte Diskurspiraterien, S. 195.

236 Schulze/Wamper, Adolf, S. 195.

237 Ebd., S. 200.

238 Langebach/Raabe, Freizeit, S. 178

239 Ebd., S. 179

240 Ebd., S. 180. 
vegane oder vegetarische Essgewohnheiten und maßvoller Umgang mit Sexualität. ${ }^{241}$ Dieselbe Strömung hat ihren Platz folglich auch im NSHC gefunden. ${ }^{242}$ Dass die Musik taktisch benutzt wird, beweist unter anderem die Aussage der Band Thrima:

„Da Musik als Propagandawaffe verstanden wird und sich dadurch entsprechende Inhalte transportieren lassen, ist es positiv zu bewerten, wenn Leute außerhalb unserer Kreise dadurch leichter in Berührung kommen."243

Jegliche Annäherungsversuche an die nichtrechte Hardcoreszene wurden jedoch abgeblockt. ${ }^{244}$ Die Entwicklung von NSHC ging einher mit dem Auftreten der AN, beide sind "gleichermaßen Ausdruck einer Öffnung des Neonazismus".245

Ähnliches gilt für das Aufkommen von nationalsozialistischem Hip-Hop. Eigentlich undenkbar, aber als Mittel zum Zweck scheint auch die auf afroamerikanische Wurzeln zurückgehende Musik zu dienen. Enesess von n'Socialist Soundsystem ist der Meinung, "dass es da eine nationale Alternative geben muss, um eben gerade jüngere Deutsche ansprechen zu können“,246 sie seien „,nationale Sozialisten und keine Hip-Hopper". 247 Sie wollen damit junge Menschen erreichen, die sie mit Rechtsrock oder anderen Genres nicht erreichen können. Nicht ohne Grund ist auf der "Schüler-CD des nationalen Widerstands“248 der AN auch nationalsozialistischer Hip-Hop zu hören. Diese Spielart von rechtsextremer Musik ist noch relativ neu, aber fügt sich exakt in die Strategie der sich modernisierenden neonazistischen Bewegungen ein und vor allem gleicht sie der Strategie der AN, sich der Strategie der Linksautonomen zu bedienen.

Um eine große Klammer zu den musikalisch ausdifferenzierten Ausdrucksformen rechtsextremer Musik zu machen: Vom Rechtsrock bis zum NS-Hip-Hop begleitete die Musik die Modernisierung des rechtsextremen Spektrums, teilweise war sie sogar wegbereitend. Deshalb ist sie eines der wichtigsten Medien zur Vermittlung von Ideologie sowie zur Rekrutierung neuer Mitglieder. Dabei sind diese Modernisierungen nie vom organisierten Rechtsextremismus ausgegangen, „, sondern aus der Dynamik jugendkultureller Entwicklungen in extrem rechten Jugendszenen". 49

241 Schulze/Wamper, Adolf, S. 195-198.

242 Ebd., S. 213-216.

243 Aryan Music, Interview mit Thrima, 21.12.2009, [http://aryanmusic.net/e107_plugins/content/content.php? content.810], eingesehen 27.2.2015.

244 Schulze/Wamper, Adolf, S. 212.

245 Ebd., S. 217.

246 Youtube LLC, Axel Reichert, Das karlsruher//netzwerk fragt nach: Interview mit Enesess (n'Socialist Soundsystem), 31.3.2011, [https://www.youtube.com/watch?v=7hhi-PpmhVM], eingesehen 28.2.2015.

247 Ebd.

248 Jugend in Bewegung. Schüler-CD des nationalen Widerstands 1.0.8, o. D. (2011), [http://schulhof-cd-sponsor.1stamendment.info/SchuelerCD108.iso], eingesehen 10.12.2014

249 Langebach/Raabe, Freizeit, S. 181. 


\section{Fazit}

Junge Leute wollen was erleben - das weiß auch die extreme Rechte. Die Schaffung einer jugendaffinen Erlebniswelt zieht sich wie ein roter Faden durch die Agitationsstrategien zur Vereinnahmung jugendlicher Subkulturen von rechtsextremer Seite. Die Skinheadsubkultur war und ist eine rebellische Erlebniswelt und bereits kurz nach ihrer Entstehung in Großbritannien bildeten sich innerhalb der Szene rechtsextreme Tendenzen aus, und das noch bevor die Politik sich näher damit beschäftigte. Das hängt mit dem damaligen gesellschaftlichen Klima, aber auch mit den Verlustängsten der sich in Auflösung befindenden Arbeiterschicht zusammen. Kultfiguren wie lan Stuart wirkten im weiteren Verlauf so stark auf die Szene ein, dass große Teile nach rechts abdrifteten. In Gramscis Worten war Stuart ein „organischer Intellektueller“ innerhalb dieser Subkultur, da er nicht nur redete, sondern auch handelte.

Die Hegemonie auf der Insel war bereits erreicht, in Westdeutschland kam der Skinheadkult bereits innerlich zerrissen an. Ab Mitte der 1980er-Jahre dominierten auch dort die rechtsextremen Skinheads. In beiden Fällen wurden eher Neonazis zu Skinheads als umgekehrt und in beiden Fällen spielten die Medien dabei eine erhebliche Rolle. Eine andere Situation herrschte in Ostdeutschland, der Skinheadkult kam dort fast ausschließlich rechtsextrem aufgeladen an und die Ablehnung gegenüber dem DDR-Regime war bereits ziemlich groß. Bis zur Wiedervereinigung hatte sich die Skinheadbewegung zum Großteil von innen heraus nach rechts radikalisiert, ohne dass rechtsextreme Gruppierungen oder Parteien von außen größeren Einfluss nehmen konnten. Gerade nach den zahlreichen Verboten von neonazistischen Gruppierungen in Deutschland wurden rechtsextreme Skinheads zwischen den Parteien und freien Kameradschaften ein Teil des organisierten Rechtsextremismus. Für diese war es nicht schwer, aufgrund der rechtslastigen Diskurshoheit innerhalb der Skinheadszene einen breiten Konsens zu schaffen und den oft diffusen Hass nachhaltig zu ideologisieren. Dabei gingen die ursprünglichen subkulturellen Wurzeln großteils verloren.

Anfang der 2000er-Jahre waren Skinheads nicht mehr zeitgemäß und so modernisierte sich auch der Rechtsextremismus. Anders als die Skinheads wollten die AN von auBen andere Subkulturen vereinnahmen, besonders die linke und alternative Szene. Um möglichst viele Jugendliche anzusprechen bzw. einen Konsens mit anderen Gruppen zu erreichen, kopierten sie Symbolik, Modetrends, Aktionsformen und Lebensstile der linksautonomen und alternativen Szene. Mit der Aussicht auf eine Kulturrevolution von rechts versuchten sie, möglichst viele verschiedene Bereiche der Gesellschaft im vorpolitischen Raum zu erobern, um eine kulturelle Hegemonie zu erreichen. Dasselbe galt für das Internet als bevorzugtes Kommunikationsmedium samt virtueller rechtsextremer Parallelwelt.

Nicht wegzudenken aus dem vorpolitischen Raum ist die Musik: Bereits bei den Skinheads spielte sie - ob rechtsextrem oder nicht - eine tragende Rolle. Und gerade rechtsextreme Musiker waren es, die die Skinheadsubkultur nach und nach mit rechtsextremen Elementen anreicherten. Auf Deutschland bezogen war rechtsextreme Musik in Form des klassischen Rechtsrocks noch relativ leicht zu erkennen, da eben be- 
vorzugt auf Deutsch gesungen wurde und die Namen der Bands einschlägig waren. Ähnlich wie die rechtsextreme Skinheadkultur war der Rechtsrock vom Mainstream isoliert, sei es durch die qualitativen Mängel oder durch die gesellschaftliche Ächtung. Mit den modernisierenden Tendenzen des Rechtsextremismus kam es neben qualitativen Steigerungen zur Ausdifferenzierung der Musikgenres, in denen sich Rechtsextremisten bewegen und dieser Prozess ist untrennbar mit den AN verbunden. Dass dies oft rein taktischer Natur war, um noch mehr Menschen zu erreichen, daraus wurde kein Geheimnis gemacht.

Letzten Endes kann unterstrichen werden: Innerhalb der Skinheadkultur hat eindeutig die rechtsextreme Seite die Hegemonie erreicht. Es war ein Prozess, der sich zu einem großen Teil innerhalb der Subkultur zugetragen hat und von rechtsextremen Gruppierungen von außen noch zusätzlich verstärkt wurde. Die AN wollen dagegen von außen möglichst viele andere Subkulturen vereinnahmen und die jeweiligen vorpolitischen Räume in der öffentlichen Meinung schrittweise mit ihrer Ideologie besetzen. Denn die „öffentliche Meinung" ist nach Gramsci „aufs engste mit der politischen Hegemonie verknüpft, es ist [...] der Berührungspunkt zwischen der,Zivilgesellschaft' und der,politischen Gesellschaft', zwischen dem Konsens und der Gewalt".250

\section{Literatur}

Aschwanden, Dirk, Jugendlicher Rechtsextremismus als gesamtdeutsches Problem (Nomos Universitätsschriften Politik 56), Baden-Baden 1995.

Baron, Udo, Das Selbstverständnis von Links- und Rechtsautonomen - Ein Vergleich zweier neuer subkultureller Erscheinungsformen, in: Gerhard Hirscher/Eckhard Jesse (Hrsg.), Extremismus in Deutschland. Schwerpunkte, Vergleiche, Perspektiven, Baden-Baden 2013.

Bredel, Holger, Skinheads - Gefahr von Rechts?, Berlin 2002.

Bundesamt für Verfassungsschutz, Rechtsextremismus: Symbole, Zeichen und verbotene Organisationen, O. D. (2014), [http://www.verfassungsschutz.de/embed/broschuere-2014-03-rechtsextremismus-symbole-zeichen-und-verbotene-organisationen. pdf], eingesehen 19.2.2015.

Dornbusch, Christian/Killguss, Hans-Peter, Unheilige Allianzen. Black Metal zwischen Satanismus, Heidentum und Neonazismus, Münster 2005.

Ders./Raabe, Jan, RechtsRock, in: Forschungsjournal NSB 19, Heft 2, (2006), S. 47-52.

El-Nawab, Susanne, Skinheads - Ästhetik und Gewalt, Frankfurt am Main 2001.

Erll, Astrid, Kollektives Gedächtnis und Erinnerungskulturen. Eine Einführung, StuttgartWeimar 2005.

Farin, Klaus/Seidel-Pielen, Eberhard, Skinheads, München 20147. 
Funk-Hennings, Erika, Skinheadmusik, Ol-Musik, Nazi-Rock?, in: Jahrbuch für Volksliedforschung 40 (1995), S. 84-100.

Gerratana, Valentino, Staat, Partei, Institutionen. Politische Hegemonie der Arbeiterklasse, in: Biago de Giovanni/Valentino Gerratana/Leonardo Paggi (Hrsg.), Gramsci-Debatte 1. Hegemonie, Staat und Partei, Hamburg 1978, S. 32-47.

Gramsci, Antonio, Gefängnishefte. Kritische Gesamtausgabe, 10 Bde., Hamburg 22012.

Ders., Gefängnishefte. Kritische Gesamtausgabe, Heft 1, Bd. 1, Hamburg 22012.

Ders., Gefängnishefte. Kritische Gesamtausgabe, Hefte 2 und 3, Bd. 2, Hamburg 2012.

Ders., Gefängnishefte. Kritische Gesamtausgabe, Hefte 6 und 7, Bd. 4, Hamburg 22012.

Ders., Gefängnishefte. Kritische Gesamtausgabe, Hefte 8 und 9, Bd. 5, Hamburg 22012.

Ders., Gefängnishefte. Kritische Gesamtausgabe, Hefte 12 bis 15, Bd. 7, Hamburg 22012. Heise, Mikiya/vom Fromberg, Daniel, „Die Machtfrage stellen“. Zur politischen Theorie Antonio Gramscis, in: Andreas Merkens/Victor Rego Diaz (Hrsg.), Mit Gramsci arbeiten. Texte zur politisch-praktischen Aneignung Antonio Gramscis (Argument Sonderband Neue Folge AS 305), Hamburg 2007, S. 110-125.

International Gramsci Society, Gramsci Bibliography: 2015, 3.3.2016, [http://www.inte rnationalgramscisociety.org/bibliography/index.html], eingesehen 29.3.2016.

Jacobitz, Robin, Antonio Gramsci - Hegemonie, historischer Block und intellektuelle Führung in der internationalen Politik (Arbeitspapiere der Forschungsgruppe Europäische Gemeinschaften 5), Marburg 1991, [http://edoc.vifapol.de/opus/volltexte/ 2013/4336/pdf/a5.pdf], eingesehen 29.3.2016.

Jaschke, Hans-Gerd, Rechtsextremismus und Fremdenfeindlichkeit. Begriffe, Definitionen, Praxisfelder, Wiesbaden $2001^{2}$.

Judt, Tony, The Past is Another Country: Myth and Memory in Postwar Europe, in: Daedalus 121 (1992), S. 83-118.

Kailitz, Steffen, Politischer Extremismus in der Bundesrepublik Deutschland. Eine Einführung, Wiesbaden 2004.

Killguss, Hans-Peter/Schedler, Jan, Jugendarbeit der extremen Rechten und das Beispiel PRO KÖLN und PRO NRW, in: Alexander Häusler (Hrsg.), Rechtspopulismus als "Bürgerbewegung". Kampagnen gegen Islam und Moscheebau und kommunale Gegenstrategien, Wiesbaden 2008, S. 129-151.

Langebach, Martin/Raabe, Jan, Zwischen Freizeit, Politik und Partei: Rechtsrock, in: Stephan Braun/Alexander Geisler/Martin Gerster (Hrsg.), Strategien der extremen Rechten. Hintergründe - Analysen - Antworten, Wiesbaden 2009. 
Leggewie, Claus, Der Kampf um die europäische Erinnerung. Ein Schlachtfeld wird besichtigt, München 2011.

Ders., Kulturelle Hegemonie. Gramsci und die Folgen, in: Leviathan 15 (1987), S. 285-304.

Menhorn, Christian, Skinheads: Portrait einer Subkultur (Extremismus und Demokratie 3), Baden-Baden 2001.

Merkens, Andreas, „Die Regierten von den Regierenden intellektuell unabhängig machen". Gegenhegemonie, politische Bildung und Pädagogik bei Antonio Gramsci, in: Andreas Merkens/Victor Rego Diaz (Hrsg.), Mit Gramsci arbeiten. Texte zur politischpraktischen Aneignung Antonio Gramscis (Argument Sonderband Neue Folge AS 305), Hamburg 2007, S.157-174.

Müller, Jan-Werner, Introduction: the power of memory, the memory of power and the power over memory, in: Ders. (Hrsg.), Memory and Power in Post-war Europe. Studies in the Presence of the Past, Cambridge 2002, S. 1-35.

Pfahl-Traughber, Armin, Der „zweite Frühling“ der NPD. Entwicklung, Ideologie, Organisation und Strategie einer rechtsextremistischen Partei, Berlin 2008, [http://www.kas. de/wf/doc/kas_14498-544-1-30.pdf], eingesehen 12.1.2015.

Ders., Politisches Selbstverständnis und Gewaltorientierung rechtsextremistischer Skinheads - Eine Fallstudie zu den Tonträgern der Band "Landser", in: Jahrbuch Extremismus \& Demokratie 13 (2001), S. 169-182.

Pfeiffer, Thomas, Erlebniswelt Rechtsextremismus. Menschenverachtung mit Unterhaltungswert, in: Caroline Y. Robertson-von Trotha (Hrsg.), Rechtsextremismus in Deutschland und Europa. Rechts außen - Rechts ,Mitte'? (Kulturwissenschaft interdisziplinär 7), Baden-Baden 2011, S. 117-131.

Ders., Virtuelle Gegenöffentlichkeit und Ausweg aus dem „rechten Ghetto“. Strategische Funktionen des Internets für den deutschen Rechtsextremismus, in: Stephan Braun/Alexander Geisler/Martin Gerster (Hrsg.), Strategien der extremen Rechten. Hintergründe - Analysen - Antworten, Wiesbaden 2009, S. 290-307.

Raabe, Jan/Langebach, Martin, Jugendkulturelle Dynamik - Vom Hardcore über den NSHC zu den "Autonomen Nationalisten", in: Jan Schedler/Alexander Häusler (Hrsg.), Autonome Nationalisten. Neonazismus in Bewegung, Wiesbaden 2011, S. 154-166.

Richter, Stefan, "Gehasst - Verdammt - Vergöttert". Das Phänomen der ehemaligen Skinhead-Kultband "Böhse Onkelz" und ihre Bezüge zum Rechtsextremismus, in: Herbert Kloninger (Hrsg.), Rechtsextremismus als Gesellschaftsphänomen. Jugendhintergrund und Psychologie, Brühl 2006, S. 110-189, [http://edoc.vifapol.de/op us/volltexte/2009/1249/pdf/band_27.pdf], eingesehen 15.1.2015.

Riechers, Christian, Antonio Gramsci. Marxismus in Italien, Frankfurt am Main 1970.

Roth, Gerhard, Gramscis Philosophie der Praxis. Eine neue Deutung des Marxismus, Düsseldorf 1972. 
Sager, Tomas, Freund oder Feind? Das widersprüchliche Verhältnis von „Autonomen Nationalisten", NPD und neonazistischer Kameradschaftsszene, in: Jan Schedler/Alexander Häusler (Hrsg.), Autonome Nationalisten. Neonazismus in Bewegung, Wiesbaden 2011, S. 105-120.

Sander, Ekkehard, Skinheads - Gefangene des eigenen Mythos?, in: Deutsches Jugendinstitut (Hrsg.), Gewalt gegen Fremde. Rechtsradikale, Skinheads und Mitläufer, München 1993, S. 161-172.

Ders., Übernahme von Ästhetik und Aktionsformen der radikalen Linken - Zur Verortung der "Autonomen Nationalisten" im extrem rechten Strategiespektrum, in: Stephan Braun/Alexander Geisler/Martin Gerster (Hrsg.), Strategien der extremen Rechten. Hintergründe - Analysen - Antworten, Wiesbaden 2009, S. 332-357.

Schneider, Helmut, Jugendlicher Rechtsextremismus in Deutschland seit 1945: Organisationen und Dispositionen, Kontinuitäten und Diskontinuitäten. Ein Literaturbericht, in: Deutsches Jugendinstitut (Hrsg.), Gewalt gegen Fremde. Rechtsradikale, Skinheads und Mitläufer, München 1993, S. 69-96.

Schulze, Christian/Wamper, Regina, "Adolf H. didn't booze or smoke”. Konsumkritik, Jugendkultur, Drogenverzicht von Rechts: Die neonazistische Adaption von Hardcore und Straight Edge, in: Regina Wamper/Helmut Kellersohn/Martin Dietzsch (Hrsg.), Rechte Diskurspiraterien. Strategien der Aneignung linker Codes, Symbole und Aktionsformen, Münster 2010, S. 194-223.

Senatsverwaltung für Inneres und Sport Berlin, Rechtsextremistische Musik, o.D. (Dezember 2012), [http://www.berlin.de/imperia/md/content/seninn/verfassungssch utz/musik_brosch_re_online.pdf?start\&ts=1355837361\&file=musik_brosch_re_online.pdf], eingesehen 13.2.2015.

Staud, Toralf/Radke, Johannes, Neue Nazis. Jenseits der NPD: Populisten, Autonome Nationalisten und der Terror von Rechts, Köln $2012^{2}$.

Stiehm, Enno, Rechtsextreme Jugendliche. Erkennungsmerkmale, Begriffe, Erklärungsansätze und schulische Handlungsmöglichkeiten, Hamburg 2012.

Stöss, Richard, Rechtsextremismus im Wandel, Berlin 2010³, [http://library.fes.de/pdffiles/do/08223.pdf], eingesehen 4.1.2015.

Suermann, Lenard, Rebel Without a Course. Der Diskurs um die „Autonomen Nationalisten", in: Regina Wamper/Helmut Kellersohn/Martin Dietzsch (Hrsg.), Rechte Diskurspiraterien. Strategien der Aneignung linker Codes, Symbole und Aktionsformen, Münster 2010, S. 166-193.

Troebst, Stefan, Geschichtspolitik. Politikfeld, Analyserahmen, Streitobjekt, in: Etienne Francois/Kornelia Konczal/Robert Traba/Stefan Troebst (Hrsg.), Geschichtspolitik in Europa seit 1989. Deutschland, Frankreich und Polen im internationalen Vergleich (Moderne europäische Geschichte 3), Göttingen 2013, S. 15-34. 
Verfassungsschutz Norrhein-Westfalen, Skinheads und Rechtsextremismus, Düsseldorf 2001, [http://www.mik.nrw.de/fileadmin/user_upload/Redakteure/Verfassungsschutz/ Dokumente/Skinheads_und_Rechtsextremismus.pdf], eingesehen 3.12.2015.

Dies./Sturm, Michael/Häusler, Alexander, Faschistischer Selbstbedienungsladen? Aneignungspraktiken der "Autonomen Nationalisten" in historischer und diskursanalytischer Perspektive, in: Jan Schedler/Alexander Häusler (Hrsg.), Autonome Nationalisten. Neonazismus in Bewegung, Wiesbaden 2011,S. 284-302.

Wetzstein, Thomas A./Dahm, Hermann/Steinmetz, Linda, Datenreisende. Die Kultur der Computernetze, Opladen 1995.

\section{Abbildungen}

Abbildung 1: Blog: Aber hier leben? Nein danke! Gegen die alltäglichen Zumutungen der Provinz, Autonom und National, 22.7.2010, [http://afg.blogsport.de/images/agg2. JPG], eingesehen 29.3.2016.

Abbildung 2: Blog: Autonome Nationalisten Wetzlar, Flugblattaktion in Marburg Freie Kräfte Frankenberg/Waldeck, 13.5.2012, [https://logr.org/anwetzlar/2012/05/13/flugbla ttaktion-in-marburgwww-unser-wa-fkb-tk/], eingesehen 29.3.2016.

Abbildung 3: Blog: Straßenkunst.info, Author Archives: strassenkunst, 5.6.2013, [https:// logr.org/strassenkunst/archives/author/strassenkunst/page/6], eingesehen 29.3.2016.

\section{Quellen}

Altermedia Deutschland, Wie organisieren wir den Widerstand, 21.10.2012, [http://altermedia-deutschland.info/content.php/2413-Wie-organisieren-wir-den-Widerstand], eingesehen 15.2.2015.

Antisem Versand, Startseite, o. D., [http://www.antisem.it/], eingesehen 24.2.2015.

Aryan Music, Interview mit Thrima, 21.12.2009, [http://aryanmusic.net/e107_plugins/ content/content.php?content.810], eingesehen 27.2.2015.

Autonome Nationalisten Göppingen, Autonom?, o. D., [http://angp.demo-goepping en.org/autonom/], eingesehen 24.2.2015.

Autonome Nationalisten Mecklenburg \& Pommern, Wofür trittst du ein? 8 Fragen an einen nationalen Sozialisten, o. D., [http://logr.org/anmup/2013/09/20/wofuer-trittstdu-ein-8-fragen-an-einen-nationalen-sozialisten/], eingesehen 20.2.2015.

Autonome Nationalisten Ostfriesland, Auf auf ins neue Kampfjahr 2010!, 2.1.2010, [https://logr.org/leerostfriesland/2010/01/02/auf-auf-ins-neue-kampfjahr-2010/], eingesehen 28.3.2016.

Autonome Nationalisten Ostfriesland, Nützliches, o. D., [http://logr.org/leerostfriesland /nutzliches/], eingesehen 16.2.2015. 
Blog: Autonome Nationalisten Ostfriesland, Über uns, November 2008, [http://logr.org/ leerostfriesland/uber-uns/], eingesehen 27.11.2014.

Blog: Autonome Nationalisten Stormarn, Autonome Nationalisten Stormarn, 30.10.2010, [http://logr.org/anstormarn/], eingesehen 20.2.1015.

Blog: Autonome Nationalisten Vorderpfalz, Warum Autonom?, o. D., [http://logr.org /autonomenationalistenvorderpfalz/was-wir-wollen/warum-autonom/], eingesehen 15.2.2015.

Blog: Straßenkunst.info, Startseite, o. D., [http://logr.org/strassenkunst/index.html], eingesehen 21.1.2015.

Blog: Metal Hall eZine, Elric, Lemmy Answers Your Questions, 17.4.2008, [http://met alhall.blogspot.co.at/2008/04/lemmy-answers-your-questions.html], eingesehen 9.1.2015.

Blood \& Honour, Home, o. D., [http://www.bloodandhonour.net/index.html], eingesehen 12.1.2015.

Bundesgerichtshof, Beschluss vom 22. April 2003, 22.4.2003, [http://juris.bundesge richtshof.de/cgi-bin/rechtsprechung/document.py?Gericht=bgh\&Art=en\&nr=26144\& pos=0\&anz=1], eingesehen 5.2.2015.

Die Rechte, Landesverband NRW gegründet, 16.9.2012, [http://die-rechte.com/landes verband-nrw-gegruendet/], eingesehen 15.2.2015.

Die Toten Hosen, Patrick Orth, März 2005, [http://www.dietotenhosen.de/band/freun de-des-hauses/patrick-orth], eingesehen 12.1.2015.

Internet Archive, Autonome Nationalisten - Wolfenbüttel/Salzgitter, 26.2.2013, [http:// web.archive.org/web/20130226203436/http://www.an-wfsz.info/?page_id=1771] eingesehen 19.2.2015.

Freie Kräfte - Schwarzwald-Baar-Heuberg, Kampf gegen Phantom-Gewalttäter in Villingen-Schwenningen, 22.1.2012, [http://fk-sbh.net/2012/01/kampf-gegen-phantomgewalttater-in-villingen-schwenningen/], eingesehen 21.1.2015.

Freie Nationalisten Siegerland, Nationale "Recht-auf-Zukunft" - Demonstration in Recklinghausen, 1.12.2009, [https://fnsi.wordpress.com/2009/12/01/nationale-\%E2\% 80\%9Erecht-auf-zukunft-demonstration\%E2\%80\%9C-in-recklinghausen/], eingesehen 21.1.2015.

Jugend in Bewegung. Schüler-CD des nationalen Widerstands 1.0.8, o. D. (2011), [http:// schulhof-cd-sponsor.1st-amendment.info/SchuelerCD108.iso], eingesehen 10.12.2014. Logr Bloghosting, Impressum, o. D., [http://logr.org/impressum/], eingesehen 23.2.2015. Logr Bloghosting, Startseite, O. D., [http://logr.org/], eingesehen 23.2.2015.

Marshall, George, Spirit of '69. A Skinhead Bible, Dunoon 1994². 
Metapedia, Willkommen bei Metapedia, o.D., [http://de.metapedia.org/wiki/Hauptseite], eingesehen 23.2.2015.

NPD-Parteipräsidium, Unsere Fahnen sind schwarz - unsere Blöcke nicht!, 15.8.2007, S. 1, [http://www.npd-kiel.de/Archiv/2007/PDF_Dateien/Akt_Aufruf_PV.pdf], eingesehen 15.2.2015.

Sicherheitshinweise für Nationalisten, Recherche gegen Linkskriminelle, o. D., [http://www. s-f-n.org/allgemeine-hinweise/anti-antifa-recherchen/2.html], eingesehen 21.1.2015.

Worch, Christian, Über freien und autonomen Nationalismus, 25.1.2005, [http://web.ar chive.org/web/20070228045353/http://1 mai.net/], eingesehen 15.2.2015.

Youtube LLC, 19Thunder90, Böhse Onkelz - Deutschland, 4.8.2012, [https://www.youtube.com/watch?v=tCqGcelhvjw], eingesehen 15.1.2015.

Youtube LLC, Axel Reichert, Das karlsruher//netzwerk fragt nach: Interview mit Enesess (n'Socialist Soundsystem), 31.3.2011, [https://www.youtube.com/watch?v= 7hhi-PpmhVM], eingesehen 28.2.2015.

Youtube LLC, Das Reich, Frank Rennicke Schlesien uns von Gott Gegeben Deutsche Musik, 7.6.2014, [https://www.youtube.com/watch?v=2IxGNQbsXIY], eingesehen 26.2.2015.

Youtube LLC, DK Snopy, Landser - Niemals, 29.11.2014, [https://www.youtube.com/ watch?v=puDO8nypFfM], eingesehen 12.2.2015.

Youtube LLC, Frei.Onkel, Böhse Onkelz - Fahrt zur Hölle |+Text, 1.7.2014, [https:// www.youtube.com/watch?v=XY9VhYDKmPg], eingesehen 12.2.2015.

Youtube LLC, Kanal von ANBueckeburg, Annett - Zeit, zu rebellieren, 1.11.2011, [https://www.youtube.com/watch?v=RywJbVwlobY], eingesehen 26.2.2015.

Youtube LLC, Kanal von Kautzmusik, Böhse Onkelz - Bunkerskins - Live in Berlin 1985 Komplett, 10.7.2013, [https://www.youtube.com/watch?v=nGuKNI1Hy_A], eingesehen 16.1.2015.

Youtube LLC, Kanal von XxxjohndeerexxX, Böhse Onkelz - Deutschland den Deutschen HQ (demo-album), 2.2.2012, [https://www.youtube.com/watch?v=gYpf UlnTNR8], eingesehen 15.1.2015.

Youtube LLC, Lukas Martin Hopfner, Böhse Onkelz - Frankreich '84, 25.2.2008, [https:// www.youtube.com/watch?v=PfKyn1/1 u8o], eingesehen 16.1.2015.

Youtube LLC, Max Gaozza, SkrewDriver - Win Or Die, 13.6.2013, [https://www.yout ube.com/watch?v=OQ2fZKhtuWY], eingesehen 7.1.2015.

Youtube LLC, Michael Wagner, Frank Rennicke - Birthday im April, 19.4.2014, [https: //www.youtube.com/watch?v=_cQSsq-LVro], eingesehen 26.2.2015.

Youtube LLC, Midgard, BÖHSE ONKELZ - Heilige Lieder, 23.2.2009, [https://www.y outube.com/watch?v=Qv4fkiLnIDk], eingesehen 12.2.2015. 
Youtube LLC, miralis dhiskoloss, Böhse Onkelz - Türken Raus, 19.4.2008, [https://WW w.youtube.com/watch?v=vJRtyu6xIw8], eingesehen 15.1.2015.

Youtube LLC, pamadere, Frank Rennicke - Rudolf Hess, 14.12.2011, [https://www.you tube.com/watch?v=N-XdeSZghok], eingesehen 26.2.2015.

Youtube LLC, PatrioticTrailerAct, Werde Unsterblich - Demonstration in Bautzen, 2.5.2011, [https://www.youtube.com/watch?v=bkU6KTjLTYU], eingesehen 24.2.2015.

Youtube LLC, poopietreat666, Absurd - Asgardsrei - Germanien über alles (Remixed, Revised \& Remastered), 12.7.2012, [https://www.youtube.com/watch?v=olfbpArtn8s], eingesehen 26.2.2015.

Youtube LLC, skhldfl, Annett - WIR HASSEN KINDERSCHÄNDER, 16.2.2008, [http s://www.youtube.com/watch?v=Idu3kB8_r90], eingesehen 26.2.1015.

Youtube LLC, WiderstandMusik, Stahlgewitter - Auf das der Adler wieder fliegt [HQ], 18.9.2014, [https://www.youtube.com/watch?v=ipcSAZDR31M], eingesehen 12.2.2015.

Tobias Leo ist Student der Geschichtswissenschaften im 7. Semester an der Universität Innsbruck.tobias.leo@student.uibk.ac.at

\section{Zitation dieses Beitrages}

Tobias Leo, Der Nazis neue Kleider: Die Vereinnahmung jugendlicher Subkulturen durch die extreme Rechte in Deutschland, in: historia.scribere 8 (2016), S. 83-124, [http://historia.scribere.at], 2015-2016, eingesehen 14.6.2016 (=aktuelles Datum).

Creative Commons Licences 3.0 Österreich unter Wahrung der Urheberrechte der Autorlnnen. 
